\title{
ANÁLISIS DEL CÓDIGO PENAL EN MATERIA DE VIOLENCIA DE GÉNERO CONTRA LAS MUJERES DESDE UNA PERSPECTIVA TRANSVERSAL
}

\author{
María ACALE SÁNCHEZ \\ PROFESORA TITULAR DE DERECHO PENAL \\ UNIVERSIDAD DE CÁDIZ
}

\section{Acercamiento}

Emprender el estudio de los «delitos de violencia de género» es una tarea que puede llevarse a cabo en dos direcciones distintas. La más rápida consistiría en acudir directamente a los tipos penales que fueron objeto de reforma a través de la Ley Orgánica $1 / 2004$, de 28 de diciembre, de medidas de protección integral frente a la violencia de género. No obstante, si se parte de que su art. I define qué se entiende por violencia de género, haciendo referencia expresa a un conjunto concreto de conductas -que son constitutivas de delito-, quizás sea conveniente comenzar por él. Inmediatamente saltará a la vista que ni todos los delitos que han sido reformados se encuentran allí reflejados, ni todos los que allí se incluyen han visto sus penas modificadas; lo que en cierta medida no deja de ser sorprender, a la vez que pone de manifiesto que lo que tenía que haber sido techo y suelo de la reforma -el concepto de violencia de género-, no lo ha sido².

En efecto, es el art. I de la LO I/2004 el que se define esta clase de violencia de la siguiente forma:

«1. La presente Ley tiene por objeto actuar contra la violencia que, como manifestación de la discriminación, la situación de desigualdad y las relaciones de poder de los hombres sobre las mujeres, se ejerce sobre éstas por parte de quienes sean o hayan sido sus cónyuges o de quienes estén o hayan estado ligados a ellas por relaciones similares de afectividad, aun sin convivencia.

2. Por esta Ley se establecen medidas de protección integral cuya finalidad es prevenir, sancionar y erradicar esta violencia y prestar asistencia a sus víctimas.

${ }^{\mathrm{I}}$ En adelante, $\mathrm{LO}$ I/2004.

${ }^{2}$ En extenso, puede verse: M. ACALE SÁNCHEZ, La discriminación hacia la mujer por razón de género en el Código penal, ed. Reus, Madrid, 2006, pp. 63 y ss; de la misma: «El artículo primero de la Ley Orgánica I/2004, de 28 de diciembre, de protección integral contra la violencia de género: el concepto de violencia de género», en P. FARALDO CABANA (dira.), Política criminal $y$ reformas penales, ed. Tirant lo Blanch, Valencia, 2007, pp. 35 y SS. 
3. La violencia de género a que se refiere la presente Ley comprende todo acto de violencia física y psicológica, incluidas las agresiones a la libertad sexual, las amenazas, las coacciones o la privación arbitraria de libertad».

El estudio que aquí se va a realizar sobre los «delitos de violencia de género» no puede pasar por alto las Sentencias del Tribunal Constitucional que, al día de hoy, han venido a corroborar la constitucionalidad de la redacción dada por la LO I/2004 al delito de mal trato singular en el ámbito familiar del art. I53.I. La primera de dichas Sentencias ha sido la número 59/2008, de I4 de mayo. Pero a ella le han seguido en cascada otras: son las números 76/2008, de 3 de julio; 8I, 82 y 83/2008, de I7 de julio; 95, 96, 97, 98, 99 y I00/2008, de 24 de julio. Todas ellas vienen a repetir los argumentos alegados en la primera, aunque quizás -si cabe- se pudiera destacar -en parte- la número 96/2008, en la medida en que analiza de forma particular el caso de los malos tratos mutuos, cuestión sobre la cual las anteriores sentencias no se habían manifestado expresamente. A este cuerpo de jurisprudencia constitucional ha venido hace pocos días a sumarse la Sentencia del mismo Tribunal número 45/2009, de I9 de febrero, en la que se ha sometido a examen el delito de amenazas del art. I7I.4, concluyéndose que tampoco en este caso se trata de una norma que pueda ser declarada inconstitucional por los mismos motivos expresados en la primera de todos estos pronunciamientos constitucionales.

Los motivos de inconstitucionalidad invocados en instancia vienen a coincidir en todas ellas en la supuesta vulneración de los principios de igualdad ante la ley, de culpabilidad, dignidad de la persona y presunción de inocencia y, al hilo del estudio de cada uno de ellos, se analiza la proporcionalidad de la respuesta penal ${ }^{4}$ (aunque en las SSTC 99/2008, de 24 de julio y 45/2009, de i9 de febrero, dicho principio se invoca como canon autónomo de constitucionalidad, aunque no aportan nada que no hubieran dicho ya las sentencias anteriores) $)^{5}$.

Ha de señalarse no obstante que todavía se esperan otras tantas sentencias de dicho Tribunal sobre el mismo art. I53, pero también sobre los delitos de amenazas leves art. I7I-, las lesiones agravadas -art. I48- y coacciones también leves -art. I72.2. En este sentido, se ha afirmado que el hecho de que ya exista un pronunciamiento de dicho Tribunal en torno a uno de los delitos objeto de reforma por la LO I/2004, es antesala de lo

\footnotetext{
${ }^{3}$ Con el tiempo, las Comunidades Autónomas van aprobando sus correspondientes leyes en desarrollo de la LO I/2004 (Ley 5/2005, de 20 de diciembre, integral contra la violencia de género de Madrid; Ley I/2004, de I de enero, integral para la prevención de la violencia contra las mujeres y la protección a sus víctimas de Cantabria; Ley I6/2003, de 8 de abril, de prevención y protección integral de las mujeres contra la violencia de género de Canarias; Ley foral 22/2002, de 2 de julio, para la adopción de medidas integrales contra la violencia sexista de Navarra; Ley 5/200I, de I7 de mayo, de prevención de malos tratos de Castilla-La Mancha; Ley II/2007, de 27 de julio, gallega para la prevención y el tratamiento integral de la violencia de género; Ley 13/2007, de 26 de noviembre, de medidas de prevención y protección integral contra la violencia de género de Andalucía; Ley 4/2007, de 22 de marzo, de prevención y protección integral a las mujeres víctimas de violencia en Aragón; Ley $7 / 2007$, de 4 de abri, para la igualdad entre mujeres y hombres, y de protección contra la violencia de género de Murcia; Ley Foral I2/2003, de 7 de marzo, de modificación de la Ley Foral 22/2002, de 2 de julio, para la adopción de medidas integrales contra la violencia sexista de Navarra; Ley 5/2008, de 24 de abril, del derecho de las mujeres a erradicar la violencia machista de Cataluña): pues bien, basta con leer los distintos conceptos de violencia de género sobre los que pivotan cada una de ellas para comprobar cómo cada una de ellas ha incorporado especificaciones sobre la definición nacional, lo que da lugar a la existencia de tantos conceptos de violencia de género, como CCAA los definen. De esta forma, se reconocen más beneficiarias de ayudas públicas en el ámbito autonómico, que en el nacional. Ha de advertirse, no obstante, que a efectos penales, dichas normas autonómicas no incorporan nada nuevo, porque la penal, como es sabido, es una competencia exclusiva del Estado central.

En la línea de interpretación del Tribunal Constitucional en virtud de la cual, «el principio de proporcionalidad no constituye en nuestro ordenamiento constitucional un canon de constitucionalidad autónomo cuya alegación pueda producirse de forma aislada respecto de otros preceptos constitucionales» (STC 55/1996, de 28 de marzo). Vid el análisis que realiza de esta cuestión N.J. DE LA MATA BARRANCO, El principio de proporcionalidad penal, ed. Tirant lo Blanch, Valencia, 2007, pp. 43 y ss.

${ }^{5}$ Vid. el estudio que realiza P. LAURENZO COPELLO («La violencia de género en la Ley integral. Valoración político criminal», en Revista Electrónica de Ciencia penal y Criminología (RECPC 07-08/2005), pp. II y ss) sobre el principio de igualdad y el mandato de no discriminación.
} 
que queda por venir, en la medida en que se advierte que los pronunciamientos que se esperan no van a ser distintos ${ }^{6}$. No obstante, aunque a nadie se le escape que con estas sentencias se ha dejado «clara» la constitucionalidad de las líneas principales de la reforma operada en el Código penal, sin duda, existen cuestiones específicas de los en los delitos de lesiones agravadas (en los que no se ha previsto potestativamente la atenuación de la pena que se contempla en los demás delitos objeto de reforma por la LO I/2004) y de coacciones también leves (en el que la coacción leve al resto de las personas a que se refiere el art. I73.2 es meramente constitutiva de falta de coacciones, no delito), que han de dar lugar necesariamente a una respuesta individualizada.

Con carácter preliminar ha de dejarse solventada la cuestión relativa a la «modalidad» de sentencia emitida por el Tribunal Constitucional (tanto la número 59/2008, de I4 de mayo, como del resto). Siguiendo a DÍAZ REVORIO, es posible distinguir dos clases de sentencias. Las primeras son las denominadas «ordinarias», que son aquellas que «recaen sobre disposiciones unívocas o sobre aquellas cuyos significados conocidos son todos ellos constitucionales o inconstitucionales» ${ }^{7}$; frente a ellas, se encuentran las denominadas «interpretativas», que «recaen normalmente sobre disposiciones ambiguas, de las que puede derivar varias normas alternativamente, aunque también pueden recaer sobre disposiciones complejas, de las que derivan varias normas conjuntamente» ${ }^{8}$, dentro de las cuales distingue las interpretativas «desestimatorias», aquéllas que declaran que el precepto impugnado «es constitucional, interpretado en el sentido impugnado en el fundamento $n^{\circ} . .$. , o que señalan que el precepto es constitucional, salvo que se interprete...», y las interpretativas «estimatorias», que son aquéllas que declaran que «el precepto impugnado es inconstitucional si se interpreta en un determinado sentido, o salvo que se interprete en un determinado sentido»?.

Vista la clasificación realizada por el autor, se puede afirmar que la STC 59/2008, de I4 de mayo no es una sentencia ordinaria, porque no dice que el art. I53.I es constitucional, ni es inconstitucional, claramente; se trata por tanto de una sentencia interpretativa, y dentro de esta modalidad, lo es de carácter estimatoria, pues afirma que si la única interpretación que cupiera hacer el art. I53.I es la realizada en la cuestión de inconstitucionalidad, esto es, que la diferencia de pena que se establece, se realiza en «función del sexo de los sujetos activos $y$ pasivo del delito que podría ser constitutivo de una discriminación por razón de sexo prohibida por el art. ${ }_{14}$ CE Y que además podría comportar una vulneración del principio de culpabilidad. En concreto, en la lectura del precepto que el Auto de cuestionamiento respecto a sus sujetos activos y pasivos, el delito de maltrato ocasional tipificado en el art. 153.1 CP se castiga con la pena de prisión de seis meses a un año cuando el sujeto activo fuera un varón y el sujeto pasivo una mujer, mientras la misma conducta es castigada con la pena de prisión de tres meses a un año si el sujeto activo fuera una mujer y el sujeto pasivo un varón (art. 153.2 CP). La diferenciación se establecería en función del sexo y restringiría el marco de la pena imponible en sentido agravatorio, pues de la pena del art. 153.1 CP queda excluido el tramo comprendido entre tres $y$ seis meses de prisión que sí forma parte del marco penal del art. 153.2», debería declarar la inconstitucionalidad del precepto. Pero como el propio Tribunal afirma, es posible reinterpretar el contenido del art. I53 desde una perspectiva distinta a como lo hace la cuestión de constitucionalidad a la que responde, lo que impide que la norma haya sido tachada de inconstitucional.

El problema, como plantea DÍAZ REVORIO es si el Tribunal Constitucional «puede realizar un pronunciamiento de este tipo ${ }^{\mathrm{10}}$, en la medida en que los riesgos que

${ }^{6}$ E. LARRAURI PIJOÁN, «Igualdad y violencia de género», en InDret (www.indret.com), I/2009, p. I5; E. GIMBERTANT ORDEIG, Prólogo a la I4ffi edición del Código penal de Tecnos, Madrid, 2008, p. I7.

${ }^{7}$ F.J. DÍAZ REVORIO, Las sentencias interpretativas del Tribunal Constitucional, ed. Lex Nova, Valladolid, 200I. p. 53.

${ }^{8}$ F.J. DÍAZ REVORIO, Las sentencias interpretativas del Tribunal Constitucional, cit., p. 54.

${ }^{9}$ F.J. DÍAZ REVORIO, Las sentencias interpretativas del Tribunal Constitucional, cit., p. 55.

${ }^{\text {Io }}$ F.J. DÍAZ REVORIO, Las sentencias interpretativas del Tribunal Constitucional, cit., p. 38. 
existen en muchos casos de estar sustituyendo la labor que ha de desempeñar el poder legislativo, son claros. En particular, esto sucederá cuando en vez de declarar en una sentencia ordinaria la inconstitucionalidad de un precepto, se le hace decir «lo que en realidad no dice»».

La particularidad que encierra esta sentencia «interpretativa» es que, de forma distinta a lo que ha hecho el Tribunal Constitucional en otras semejantes, no ha incluido en el «fallo» la declaración de inconstitucionalidad de la interpretación que se rechaza ${ }^{\mathrm{I} 2}$. Con ello, se hubiera contribuido a visualizar que las críticas fundamentales que se han hecho al contenido de la reforma operada en el Código penal por la LO I/2004 tienen su base y que sólo haciendo ese esfuerzo por parte del órgano encargado de velar por la constitucionalidad de las normas que componen el ordenamiento jurídico español, se le permite seguir vigente. En este sentido se manifiestan algunos de los votos particulares de la Sentencia 59/2008, de I4 de mayo ${ }^{\mathrm{I3}}$ : «si la sentencia se hubiese atendido a la coherencia aconsejable con ese precedente $y$ con la afirmación condicional de la inconstitucionalidad del precepto en la interpretación de la Magistrada cuestionante,... lo normal hubiera sido que la declaración de inconstitucionalidad de esa interpretación se hubiese llevado al fallo, sin perjuicio de dejar a salvo las otras interpretaciones que la Sentencia (no yo, por supuesto) declara como posibles».

Por ello, ha de afirmarse que la cuestión de inconstitucionalidad planteada por el Juzgado de lo Penal número 4 de Murcia de 29 de julio de 2005 ha valido para que el Tribunal Constitucional haya declarado inconstitucional una determinada lectura del art. I53.I, así como simultáneamente, para que señalara cuál es la interpretación constitucional ajustada que ha de hacerse de la letra de la ley, sin duda alguna inspirado por el principio de conservación de la ley, que es el que «explica estas decisiones y les sirve de fundamento» ${ }^{\mathrm{T} 4}$. Y en esta línea, el esfuerzo demostrado por la magistrada ponente de la cuestión de inconstitucionalidad, no ha quedado en saco roto, pues como afirma DÍAZ REVORIO, «todo precepto que no es totalmente constitucional, es parcialmente inconstitucional, $y$ así debería declararse expresamente» ${ }^{15}$. Esto es lo que manifiesta uno de los votos particulares: «la Sentencia implícitamente está declarando la inconstitucionalidad del precepto cuestionado en la interpretación que se atiene a la pura literalidad de su texto sin más, es decir, sin incorporar un nuevo elemento al tipo, $y$ al propio tiempo declarando su constitucionalidad sobre la base de que concurra aquella situación de discriminación, desigualdad o relación de poder que, si atendemos 'al espíritu y finalidad' de la norma -art. 3.1 del Título preliminar del Código civil-, resulta ser elemento del tipo»'

\section{Las reformas penales}

\section{II.I Cuestiones comunes: autoría, sujeto pasivo y circunstancias modificativas de la responsabilidad criminal}

En particular, las modificaciones del Código penal operadas por la LO I/2004 han sido variadas, como se verá posteriormente y en común tienen todas ellas muchas cosas. En este momento van a destacarse dos bloques: por un lado, el relativo a la autoría y a los

\footnotetext{
"F.J. DÍAZ REVORIO, Las sentencias interpretativas del Tribunal Constitucional, p. 297.

${ }^{\mathrm{I} 2}$ F.J. DÍAZ REVORIO, Las sentencias interpretativas del Tribunal Constitucional, cit., p. 55.

${ }^{13}$ Votos particulares que formulan los magistrados Conde Martín de Hijas, Delgado Barrio y RodríguezZapata Pérez.

${ }^{\mathrm{I}}$ F.J. DÍAZ REVORIO, Las sentencias interpretativas del Tribunal Constitucional, cit., p. 53.

${ }^{15}$ F.J. DÍAZ REVORIO, Las sentencias interpretativas del Tribunal Constitucional, cti., pp. I6г у 290.

${ }^{16}$ Voto particular que formula el magistrado Delgado Barrio.
} 
sujetos pasivos y, por otro, el que se refiere a las circunstancias modificativas específicas de la responsabilidad criminal; ambas cuestiones comunes han tenido una decisiva importancia en el análisis que, sobre la constitucionalidad de los delitos de mal trato singular del art. I53.I y de amenazas leves con armas $u$ otros instrumentos del art. I7I.4 ha realizado el Tribunal Constitucional en sus Sentencias 59/2008, de I4 de mayo y 45/2009, de iو de febrero. El hecho de que se trate de cuestiones comunes, y que por tanto se repitan en idéntico sentido en sede de coacciones leves, permite augurar que volverán a ocupar en el futuro constitucional próximo el centro de la atención.

En materia de autoría, ha de señalarse que los delitos que han visto reformadas sus penas por la LO I/2004 castigan -en primer lugar- a «el que» llevare a cabo tales conductas, «cuando la ofendida sea o haya sido esposa, o mujer que esté o haya estado ligada a él por una análoga relación de afectividad aun sin convivencia». A pesar de que la forma utilizada por el legislador para definir al sujeto activo sea neutra, ha de entenderse que sólo puede serlo un hombre -que además mantenga o haya mantenido una concreta relación con la víctima- ${ }^{\mathrm{I}}$. En efecto, basta con atender a la letra del art. I de la LO I/2004 en la que se define la clase de violencia que quiere prevenir, erradicar y sancionar: «la violencia que, como manifestación de la discriminación, la situación de desigualdad y las relaciones de poder de los hombres sobre las mujeres, se ejerce sobre éstas por parte de quienes sean o hayan sido sus cónyuges o de quienes estén o hayan estado ligados a ellas por relaciones similares de afectividad, aun sin convivencia». El Tribunal Constitucional en su Sentencia 59/2008, de I4 de mayo ha venido a afirmar que ello no obstante, nada impediría que fuera también una mujer el sujeto activo pues la letra de la ley utiliza un lenguaje neutro, si bien, por los razonamientos que realiza a continuación -la concreción del bien jurídico protegido-, elimina del ámbito de la autoría de la violencia de género a las mujeres.

De esta forma, se deja fuera del núcleo de los sujetos activos, a la mujer que está o estuvo casada o unida sentimentalmente con otra mujer, con o sin convivencia, olvidando que también en estos casos puede existir violencia de género contra una víctima mujer, por una autora de sexo femenino que puede haber adoptado en la pareja el rol que tradicionalmente adopta en las relaciones heterosexuales el hombre y que por tanto actúe con la finalidad de discriminar a su esposa. Pero por lo mismo, tampoco se otorga protección a las relaciones homosexuales masculinas en este caso, porque ninguno de los miembros de la pareja es de sexo femenino, adopte el rol que adopte en la relación ${ }^{\mathrm{r} 8}$. Nada por el contrario impediría la subsunción en caso de personales transexuales, lo que no debería pasar desapercibido.

Con ello, se está poniendo de manifiesto que se trata de una definición de violencia de género, ha de ceñirse a una clase concreta: a saber, la violencia de género en razón de sexo, olvidando que si bien con el sexo se nace, el género se aprehende durante la vida. Es lo que señala acertadamente MAQUEDA ABREU cuando afirma que la «la explicación de la violencia contra las mujeres en clave cultural, no biológica es la que define la perspectiva de género» ${ }^{\text {19 }}$.

La exclusión de las relaciones homosexuales en este punto de los tipos penales, no significa sin embargo que en caso de violencia no se les ofrezca una protección y sanción «similar» a la analizada. En efecto, en relación a la autoría y los sujetos pasivos de estos delitos, y a pesar de la taxatividad del art. I de la LO I/2004 en lo que a las personas

\footnotetext{
${ }^{17}$ Véase por todos: J.M. TERRADILLOS BASOCO, «Incidencia de la posición o situación personal, pública y privada, en la responsabilidad criminal», en Cuadernos de Derecho Judicial, Consejo General del Poder Judicial, I995 (VII), p. 83 y ss.

${ }^{18}$ Critica la exclusión de las mujeres como sujeto activo E. LARRAURI PIJOÁN, «Igualdad y violencia de género», cit., p. 6.

${ }^{19}$ M.L. MAQUEDA ABREU, «La violencia de género: entre el concepto jurídico y la realidad social», en Revista Electrónica de Ciencia penal Y Criminología (RECPC ०8-02/2006), pp. 2-3.
} 
beneficiarias de los derechos económicos, sociales y laborales que se reconocen en su interior se refiere, las reformas que dicha Ley operó en el corazón del Código penal han sobrepasado aquel contorno, en la medida en que durante su tramitación parlamentaria, en el Título relativo a la «tutela penal» se incluyó una segunda categoría de víctimas: «las personas especialmente vulnerables que convivan con el autor», con la finalidad de evitar previsibles y futuras declaraciones de inconstitucionalidad por violación del principio de igualdad ante la ley penal. Ello se pone de manifiesto si se atiende a los debates suscitados en el ámbito parlamentario y, en particular, a la intervención del Sr. Villarrubia, quien afirmó que con la inclusión de este segundo colectivo en las reformas operadas en el Código penal «se lima así, incluso intelectualmente, una serie de aristas que había desde el punto de vista de quienes sostenían la posible inconstitucionalidad de este proyecto, $y$ aunque en ningún caso existía, quitamos ese debate $y$ no por razones de constitucionalidad sino por razones de oportunidad politica» ${ }^{20}$.

Puede concluirse en este momento que si bien con carácter general la finalidad de la LO I/2004 es hacer frente a la violencia que sufren las mujeres a las que se refiere el art. I, las concretas finalidades perseguidas con las reformas operadas en el ámbito penal no son tan claramente confesables, en la medida en que, aunque si bien por un lado ha partido del concepto de violencia de género del art. I, ha incorporado, por otro, otra pluralidad de reformas relativas a las personas especialmente vulnerables que convivan con el autor, en las que las cuestiones relativas al sexo y a la relación que han de unir a las personas especialmente vulnerables quedan completamente al margen, con la práctica finalidad de evitar las posibles declaraciones de inconstitucionalidad de las mismas por violación del principio de igualdad en el ámbito penal. Ha procedido pues el legislador con pies de plomo: a sabiendas de lo que hacía. Cosa distinta es que lo haya conseguido.

No obstante, la protección que se ofrece a la mujer víctima de esta clase de violencia a manos de quien es o ha sido su esposo o compañero sentimental -aún sin convivencia- y la que se ofrece a las personas especialmente vulnerables que convivan con el autor, no es la misma, en la medida en que en el primer caso, se trata de una protección iuris et de iure, mientras que en el segundo, sólo es iuris tantum pues hay que someter a prueba la especial vulnerabilidad de la víctima y la convivencia. En otras palabras, en el primer caso, la especial protección se fundamenta en el sexo de los sujetos implicados y en la especial relación que les une -o que les unió en el pasado-, mientras que en el segundo, en datos relacionados con las características de la concreta víctima -su «especial» vulnerabilidad y su convivencia con el autor- $-^{2 \mathrm{~T}}$.

Por ello, el riesgo que se intentaba prevenir -evitar la declaración de inconstitucionalidad de estos preceptos por violación del principio de igualdad-, en puridad de principios, no se ha conseguido y ello a pesar de que, sorpresivamente, el Tribunal Constitucional en su esperada Sentencia 57/2008, de I4 de mayo ha ignorado esta cuestión, al afirmar que la desigual protección denunciada en la cuestión de inconstitucionalidad se solventa con la inclusión de estas personas: así, afirma que «la segunda precisión en torno a los contornos típicos del enunciado cuestionado se refiere a su inserción en un panorama normativo complejo, en el que el inciso siguiente del art. 153.1 añade como sujeto pasivo a la

\footnotetext{
${ }^{20}$ Diario de Sesiones del Congreso de los Diputados. Pleno y Diputación permanente. Año 2004. VIII Legislatura, núm. 39, Sesión Plenaria núm. 35, 7.I0.2004, p. I.722. En el mismo sentido, afirma L. ARROYO ZAPATERO («Legitimidad constitucional y conveniencia político-criminal de la Ley contra la violencia de género», en F. MUÑOZ CONDE (dir.), Problemas actuales del Derecho penal y la Criminología. Estudios penales en memoria de la Profesora Dra. Maria del Mar Díaz Pita, ed. Tirant lo Blanch, Valencia, 2008) que la inclusión en los tipos penales de las personas especialmente vulnerables que convivan con el autor «resultó un punto de encuentro para hacer posible el consenso que terminó llevando a la unanimidad parlamentaria en la votación final, lo que sin ser bueno para la coherencia intelectual y política de todos resulta buenísimo para la causa de la lucha contra la violencia de género».

${ }^{21}$ M. ACALE SÁNCHEZ, La discriminación hacia la mujer en razón de género en el Código penal, cit., pp. Iog y SS
} 
'persona especialmente vulnerable que conviva con el autor'. Con ello, queda notablemente reducida la objeción sustancial del Auto a la norma en cuestión, relativa a que se castigan más las agresiones del hombre a la mujer que es o fue su pareja (art. 153.1) que cualesquiera otras agresiones en el seno de tales relaciones y significativamente las agresiones de la mujer al hombre. Así, si respecto de las agresiones a personas especialmente vulnerables no hay restricción alguna en el sexo del sujeto activo, resultará que la misma pena que se asigna a las agresiones del varón hacia quien es o fue su pareja femenina (pena del art. 153.1) será la que merezcan las demás agresiones en el seno de la pareja o entre quienes lo fueron cuando el agredido o la agredida sea una persona especialmente vulnerable que conviva con el autor o la autora de la agresión». Con ello, se está ignorando que la protección no es la misma, en la medida en que hace falta que concurran más elementos cuando se trata de una y otra víctima (esto es, se exigen más requisitos para imponer la misma pena), con lo cual, no es posible afirmar que se ofrece idéntica protección $^{22}$ : bastaría pensar en el caso en el que la mujer autora hubiera dejado de convivir con su marido o compañero sentimental, o que aún conviviendo, no fuera posible apreciar la especial vulnerabilidad de aquél en los casos en los que lo someta a actos de violencia.

$\mathrm{Y}$ en relación con el segundo bloque de materias comunes a toda la reforma operada por la LO I/2004 en el ámbito penal, ha de señalarse que los nuevos delitos de maltrato singular, amenazas leves y coacciones leves, agravan singularmente la pena si el delito se perpetra en presencia de menores, o tenga lugar en el domicilio común o en el de la víctima, o se realice quebrantando una pena de las contempladas en el art. 48 de este Código, o una medida cautelar o de seguridad de la misma naturaleza. A ellas, y de forma específica, se añade en el delito de mal trato singular, la comisión del mismo «con armas»" En los tres delitos, la pena que le corresponderá al autor es la establecida en el tipo básico en su mitad superior. Dichas circunstancias, sin embargo, no han sido incluidas ni en el delito de lesiones del art. I48, ni en el de quebrantamiento de condena del art. 468.2. En el primer caso, porque se trataría de agravar específicamente un supuesto delito de lesiones que ya es un tipo agravado y, en el segundo, porque como se verá, en él parece que no tiene cabida la protección de bienes jurídicos personales de los que sea titular la víctima.

En todo caso, ha de tenerse en consideración que, dejando a un lado la reforma operada en el ámbito del delito de lesiones, en el que el ser la víctima la esposa o mujer que está o estuvo casada o unida sentimentalmente a su agresor de sexo masculino es un supuestos de agravación de la pena, en los delitos de mal trato, amenazas y coacciones leves, la concreta condición de la víctima es un elemento del tipo, y no constituye un mero criterio de agravación de la pena, como parece sugerir LARRAURI PIJOAN ${ }^{24}$ : es más, es el elemento central del tipo básico.

Por otra parte, también en los delitos de mal trato singular, amenazas leves y coacciones también leves, se incluye como criterio cualificado de atenuación de la pena que determina la imposición de la inferior en grado-, las circunstancias personales del autor y las concurrentes en la realización del hecho. Y, de nuevo, estas circunstancias vuelven a estar ausentes en la regulación del delito agravado de lesiones y en el de

\footnotetext{
${ }^{22}$ La interpretación en sede judicial de lo que por «personas especialmente vulnerables que convivan con el autor» ha de entenderse, no ha sido pacífica. En este sentido, por parte de un sector de la jurisprudencia (por todas, véase la Sentencia de la Audiencia Provincial de Guipúzcoa de I3 de febrero de 2007) se ha afirmado que, a pesar de que expresamente se exija ambos requisitos, el de la convivencia no es necesario cuando se trata de maltrato, amenazas, coacciones entre hermanos, en la medida en que los arts. I53, I7I y I72 se remiten al art. I73,2 en el que en efecto no se exige la convivencia. En sentido contrario se ha mostrado tanto la Fiscalía General del Estado en su Consulta I/2008, como la jurisprudencia posterior del Tribunal Supremo (Sentencia 201/2007, de I6 de marzo), exigiendo pues su prueba.

${ }^{23}$ También en el delito de malos tratos habituales se agrava la pena en virtud de las mismas circunstancias, si bien en esta sede, basta con que concurran en uno de los actos que da lugar a construir la habitualidad. Vid. M. ACALE SÁNCHEZ, «Los nuevos delitos de mal trato singular y de malos tratos habituales en distintos ámbitos, incluido el familiar», en Revista de Derecho penal y Criminología, I5/2005, pp. 38 y ss.
}

${ }^{24}$ E. LARRAURI PIJOAN, «Igualdad y violencia de género», cit., p. I4. 
quebrantamiento de condena. De esta forma, se está poniendo de relieve que cuando se proceda a analizar la constitucionalidad de estos preceptos, el Tribunal Constitucional no va a poder recurrir como argumento salvador de la constitucionalidad de los tipos el hecho de que en el caso concreto, siempre podrá el juez recurrir a ellos para garantizar la proporcionalidad de la respuesta penal ${ }^{25}$, como se verá posteriormente.

Con unas y otras, está el legislador otorgando una importancia de peso a la fase de individualización judicial de la pena ${ }^{26}$. Lo que no deja de ser sorprendente en el contexto de una reforma penal que, precisamente por la desconfianza que pone de manifiesto el legislador hacia los jueces, le tasa la respuesta, impidiéndole el arbitrio que en la LO I/2004 se le discute, al que, sin embargo, por esa misma vía, se le abre la puerta.

\section{II.2 Las concretas reformas del Código penal operadas por la LO I/2004}

La primera de las modificaciones es la que afecta a los artículos 83, 84 y 88 en materia de suspensión y sustitución de las penas, estableciendo un régimen especial cuando se trate de un supuesto de violencia de género, ante la pérdida de confianza del legislador en la labor judicial: de ahí que si bien no se anula, se limita en gran medida la discrecionalidad judicial, impidiendo que la respuesta se adapte a las características del caso concreto $^{27}$, en la medida en que «en todo caso», si deciden suspender la ejecución de la pena, habrán de acordar como pautas de comportamiento las prohibiciones de acudir a determinados lugares y de aproximarse a la víctima, o a aquellos de sus familiares $u$ otras personas que determine el juez o tribunal, o de comunicarse con ellos, así como la obligación de participar en programas formativos. En el supuesto de que se incumpla la pauta, en todo caso, de nuevo, el juez decretará el cumplimiento de la pena privativa de libertad que hubiera dejado en suspenso, en vez de aplicarle el régimen general previsto en estos casos en el art. 84, en virtud del cual, atendiendo a las características del caso concreto, podrá sustituir la pauta por otra, prolongar el plazo de ejecución y, sólo en caso de incumplimiento reiterado de la misma, decretar el levantamiento de la suspensión ${ }^{28}$.

Las especificaciones introducidas en el mecanismo de la sustitución de la pena en el ámbito de la violencia de género son dos: la pena privativa de libertad sólo podrá ser sustituida por la de trabajos en beneficio de la comunidad, impidiendo la aplicación de la pena de multa que tan fácilmente termina recayendo sobre las propias víctimas en supuestos de dependencia económica ${ }^{29}, \mathrm{y}$, además, «en todo caso», el juez, al decretarla, impondrá adicionalmente la sujeción a programas específicos de reeducación y tratamiento psicológico, las prohibiciones de acudir a determinados lugares y de aproximarse a la

${ }^{25}$ En el mismo sentido, L. ARROYO ZAPATERO, «Legitimidad constitucional y conveniencia políticocriminal de la Ley contra la violencia de género», cit., p. 730.

${ }^{26}$ E. LARRAURI PIJOAN, «Igualdad y violencia de género», cit., p. I4.

${ }^{27}$ Así, la suspensión de la ejecución de la pena, con carácter general, se adopta «atendidas las circunstancias personales del delincuente, las características del hecho y la duración de la pena» (art. 80); mientras que la sustitución de las penas privativas de libertad tiene en consideración «las circunstancias personales del reo, la naturaleza del hecho, su conducta $Y$, en particular, el esfuerzo para reparar el daño causado» (art. 88).

${ }^{28}$ Por todos véase: P. FARALDO CABANA, «Estrategias actuariales en el control penal de la violencia de género», en F. MUÑOZ CONDE (dir.), Problemas actuales del Derecho penal $\gamma$ de la Criminología. Estudios penales en memoria de la Profesora Dra. María del Mar Díaz Pita, cit., pp. 74I y ss.

${ }^{29}$ Ello determina que no pueda aplicarse el mecanismo de sustitución de la pena establecido en el art. 88.I párrafo $2 \mathrm{ffl}$, en virtud del cual, el juez o tribunal podrá sustituir «por multa o por multa y trabajos en beneficio de la comunidad, las penas de prisión que no excedan de dos años a los reos no habituales, cuando de las circunstancias del hecho $y$ del culpable se infiera que el cumplimiento de aquéllas habría de frustrar sus fines de prevención y reinserción social». 
víctima, o a aquellos de sus familiares $u$ otras personas que determine el juez o tribunal, o de comunicarse con ellos.

Centrando ahora el estudio en las reformas operadas dentro del Libro II, el primero de los delitos que sufre modificación es el previsto en la modalidad agravada de delito de lesiones del art. I48, en el que se incluyen tres nuevos criterios de agravación de la pena: en el número $2^{\circ}$, junto al ensañamiento, que ya estaba, se ha incluido la «alevosía» ${ }^{3 \circ}$; además se han incorporado otros dos nuevos, en los números 4 ffi «si la víctima fuere $o$ hubiere sido esposa, o mujer que estuviere o hubiere estado ligada al autor por una análoga relación de afectividad, aun sin convivencia» y $5^{\circ}$ «si la víctima fuera una persona especialmente vulnerable que conviva con el autor». Dichos supuestos de agravación van a operar con independencia de las circunstancias del caso y las personales del autor, que todo lo más determinarán la individualización judicial de la pena dentro del marco penológico típico, en la medida en que, como se decía anteriormente, no se ha previsto expresamente en esta sede que operen como circunstancias específicas de atenuación de la pena, como así se ha hecho en los artículos I53, I7I y I72.

También ha sido modificado, en tercer lugar, el delito de mal trato singular del art. I53, en el sentido de imponer distintas penas «cuando la ofendida sea o haya sido esposa, o mujer que esté o haya estado ligara a él por una análoga relación de afectividad aun sin convivencia, o persona especialmente vulnerable que conviva con el autor», y cuando «la víctima del delito... fuere alguna de las personas a que se refiere el art. 173.2, exceptuadas las personas contempladas en el apartado anterior de este artículo» ${ }^{31}$.

En materia de amenazas, en cuarto, se impone penas distintas si, por un lado, se amenaza de modo leve a «quien sea o haya sido su esposa, o mujer que esté o haya estado ligada a él por una análoga relación de afectividad aun sin convivencia» $\mathrm{O}$ «a una persona especialmente vulnerable que conviva con el autor» $\mathrm{y}$, por otro, si se amenaza de modo leve con armas $\mathrm{u}$ otros instrumentos peligrosos «a alguna de las personas a las que se refiere el art. 173.2, exceptuadas las contempladas en el apartado anterior de este artículo».

La reforma llevada a cabo en el ámbito de las coacciones, en quinto lugar, ha consistido en elevar a la consideración de delito las coacciones leves -antes definidas en el art. 620- si la víctima es o ha sido «esposa, o mujer que esté o haya estado ligada a él por una análoga relación de afectividad, aun sin convivencia» o «una persona especialmente vulnerable que conviva con el autor», mientras que si la víctima de la coacción leve es «alguna de las personas a que se refiere el art. 173.2», la conducta es castigada como falta en el art. 620.

En penúltimo lugar, se ha introducido un número 2 dentro del art. 468, en el que se señala que «se impondrá en todo caso la pena de prisión de seis meses a un año a los que

\footnotetext{
${ }^{30}$ El motivo por el cual se lleva a cabo su inclusión en este artículo no está del todo claro, pues se trata de una reforma que tiene validez para todos los casos que la alevosía acompañe a la lesión, con independencia de los sexos y de los sujetos implicados y de las relaciones personales o familiares que pudieran existir entre ellos. Ciertamente, el hecho de que la muerte alevosa sea considerada asesinato y que el delito de asesinato con dicha circunstancia haya sido admitido doctrinal y jurisprudencialmente sin demasiados problemas (si no fuera por las difusas fronteras de la alevosía), normaliza el debate en torno a la inclusión de la nueva circunstancia agravante en sede de delito de lesiones. Lo único que se discute en esta sede es que se haya incluido en el Código a través de una ley orgánica, la LO I/2004, que tiene un objetivo tan preciso. Por otro lado, si se observa, según el art. I48 allí se agrava la pena «atendiendo al resultado causado o al riesgo producido»; es decir, se centra en el desvalor de resultado producido por la agresión. Por ello, la inclusión de la alevosía en este artículo no se ajusta ni al resultado causado ni al riesgo producido, en la medida en que dicha circunstancia, más que afectar al resultado, afecta a la forma de causarlo, suponiendo un incremento de injusto por incrementar el desvalor de acción. Por eso choca que se incluya este criterio de agravación dentro de los que ha sido incluido.

${ }^{31}$ Véase el análisis que lleva a cabo C. VILLACAMPA ESTIARTE, «El maltrato singular cualificado por razón de género. Debate acerca de su constitucionalidad», en Revista Electrónica de Ciencia Penal y Criminología (REPDC 09-I2-2007), http://criminet.ugr.es/recpc. También, véase: J.L. RUBIDO DE LA TORRE, Ley de violencia de género. Ajuste de constitucionalidad en materia penal, ed. Tirant lo Blanch, Valencia, 2007, pp.8I y ss.
} 
quebrantaren una pena de las contempladas en el artículo 48 de este Código o una medida cautelar o de seguridad de la misma naturaleza impuestas en procesos criminales en los que el ofendido sea alguna de las personas a las que se refiere el art. 173.2».

Y finalmente, se ha procedido a modificar la falta de vejaciones leves del art. 620, aunque su aplicabilidad en los casos de violencia de género es por propia decisión legislativa puramente residual, no así en los supuestos de violencia doméstica, como se verá posteriormente ${ }^{32}$.

\section{II.3 Identificación de «las personas señaladas en el art. I73.2»}

Como se observa, todos estos preceptos de una $u$ otra forma terminan por referirse a las «personas señaladas en el art. 173.2», en cuyo interior se castiga desde la aprobación de la LO II/2003 el delito de malos tratos habituales en el ámbito familiar. La remisión obliga a proceder a analizar los delitos incorporados al Código a través de la LO I/2004 después de haber analizado las relaciones familiares que allí se señalan.

En este sentido, la redacción actual de este delito del art. I73.2 incluye en su interior una serie de «relaciones» que se equiparan valorativamente a las de naturaleza familiar, a través de otro tipo de vínculos. Y en este sentido, si bien están todas las que dan lugar a la apreciación del parentesco -art. 23-, también existe un segundo grupo que se equipara materialmente a las anteriores, y un tercero en cuyo interior, se encuentran relaciones establecidas a través de vínculos profesionales o de prestación de servicio. La inclusión de estas nuevas relaciones dentro de las que dan lugar a la aplicación del delito de malos tratos en el ámbito «familiar» fue criticada en su momento, pues no se consiguió otro objetivo que desbordar el ámbito familiar, desdibujando así el bien jurídico que tras una serie de sentencias contradictorias, había quedado dibujado en la jurisprudencia del Tribunal Supremo: la paz familiar ${ }^{33}$.

Así, en primer lugar, el art. I73.2 se refiere a todas aquellas relaciones familiares que dan lugar al nacimiento entre los ligados al parentesco: en este sentido, por lo que toca a las relaciones de pareja, se incluyen los malos tratos entre quienes son o han sido cónyuges o personas unidas por análoga relación de afectividad y los malos tratos entre novios -con independencia del sexo de los sujetos activos y pasivos-. Téngase en consideración que solo las dos primeras dan lugar en sentido estricto al nacimiento de relaciones parentales a efectos penales, en la medida en que si se observa, el art. 23 deja fuera a los novios. Junto a ellos, se incluyen los descendientes, ascendientes o hermanos por naturaleza, adopción o afinidad, propios o del cónyuge o conviviente, que también son considerados «familia» a los efectos del art. 23 .

El segundo grupo está formado por una serie tasada de relaciones equiparadas a las familiares, en particular, las relaciones que se establecen con los menores o incapaces que conviven con el agresor, o que se hallan sujetos a la potestad, tutela, curatela, acogimiento o guarda de hecho.

${ }^{32}$ Vid. M. ACALE SÁNCHEZ, «Análisis del Código penal en materia de violencia de género contra las mujeres desde una perspectiva transversal», en C. VILLACAMPA ESTIARTE (coorda.), Violencia de género $Y$ sistema de justicia penal, ed. Tirant lo Blanch, Valencia, 2008, pp. II3 y ss.

${ }^{33}$ J.M. TAMARIT SUMALLA, «Artículo I73», en G. QUINTERO OLIVARES (dir.), F. MORALES PRATS (coord.), Comentarios a la parte especial del Derecho penal, ed. Aranzadi, Pamplona, 2007, p. 267; E. LARRAURI, Criminología crítica y violencia de género, ed. Trotta, Madrid, 2007, p. 49; M. ACALE SÁNCHEZ, La discriminación hacia la mujer por razón de género en el Código penal, cit., p. 293; de la misma, «Los nuevos delitos de mal trato singular y de malos tratos habituales en distintos ámbitos, incluido el familiar», cit., p. 39 (véanse las Sentencias allí citadas). 
Y, finalmente, el tercer grupo de personas a las que se refiere el art. I73.2 está formado por aquéllas que están unidas por vínculos completamente ajenos al parentesco: se trata de la persona amparada en «cualquier otra relación» por la que se encuentre internada en el núcleo de la convivencia familiar del autor, así como de las violencias que se llevan a cabo sobre personas que «por su especial vulnerabilidad» se encuentren sometidas a custodia en centros públicos o privados, entre las que existen meras relaciones profesionales o de prestación de servicios.

De todos estos sujetos, los tipos reformados por la LO I/2004 protegen más a la mujer que es o ha sido la esposa o compañera sentimental del agresor aun sin convivencia, así como a las personas especialmente vulnerables que convivan con el autor, con independencia ya, de que se sea especialmente vulnerable y se conviva por ser pariente en sentido estricto o porque se haya convenido así mediante precio. El resto, aunque sean parientes a los efectos del art. 23, quedan dentro de la referencia en los artículos I53, I7I y 620 «a alguna de las personas a las que se refiere el art.173.2, exceptuadas las contempladas en el apartado anterior de este artículo». Con ello se está afirmando que se concede igual protección -por ejemplo-, a la esposa víctima de mal trato a manos de su marido, que al interno en una residencia geriátrica víctima de violencia a manos de un cuidador que allí resida, siempre que se le considere en este caso persona especialmente vulnerable. Esto es, se equiparan a efectos de penas, cuestiones que son completamente diversas, como consecuencia de la ampliación del círculo de sujetos protegidos en el delito de malos tratos habituales en el ámbito familiar en la reforma operada por la LO II/2003, que, como se decía, desdibujó el bien jurídico protegido. El marido o compañero sentimental se equipara al anciano residente en la residencia geriátrica siempre que, eso sí, se pruebe la convivencia así como su especial vulnerabilidad.

\section{Los delitos que no han sido reformados}

A pesar de que el art. I.3 de la LO I/2004 señale que la violencia de género allí definida se refiere a «todo acto de violencia física o psicológica, incluidas las agresiones a la libertad sexual, las amenazas, las coacciones o la privación arbitraria de libertad», no todos esos delitos han sido modificados; además, se da la circunstancia de que se ha llevado a cabo la reforma de otro delito al que no se hace referencia en el mencionado precepto -el quebrantamiento de condena.

En efecto, los delitos contra la libertad sexual no han sido objeto de reforma, sin que quede claro el motivo por el cual no se ha incluido en el interior del art. I8o un supuesto específico de agravación que tuviera en consideración, al igual que en los delitos de lesiones -art. I48-, el hecho de que la víctima sea una mujer que está o estuvo casada o unida sentimentalmente al agresor de sexo masculino aún sin convivencia o una persona especialmente vulnerable que conviva con el autor ${ }^{34}$. Por ello, habrá que acudir para la medición de la pena a la circunstancia mixta de parentesco con carácter agravante, aunque, como se decía, en su interior no va a ser posible agravar la pena en los casos de relaciones de noviazgo, ni cuando se trate de personas unidas por vínculos distintos al parentesco, lo que determinará -cuando concurra aquél- la imposición de la pena tipo en su mitad superior (art. 66). Aunque también se podrá recurrir a agravar la pena en atención a la

${ }^{34} J . J$. GONZÁLEZ RUS, «La constitucionalidad de la LO I/2004, de medidas de protección integral contra la violencia de género, en relación con la reforma de los delitos de lesiones, amenazas y coacciones», en J.C. CARBONELL MATEU y otros (coords.), Estudios penales en homenaje al Profesor Cobo del Rosal, ed. Dykinson, Madrid, 2005, p. 500. 
circunstancia prevista en el número 4 del art. 22, esto es, la agravante de discriminación en razón de sexo, siempre que se pruebe el móvil discriminatorio ${ }^{35}$.

Quizás la sexualización de la letra de la ley en unos delitos en los que desde hace años la tendencia ha sido precisamente la de eliminar las viejas referencias a un sexo y a otro como sujetos activos y pasivos, con la moralización que con ello se alcanzaba, haya frenado la intención del legislador manifestada en el art. I.3 de la LO I/2004. Se da la coincidencia, por otro lado, que las últimas reformas del delito de violación han estado dirigidas a la vez que a delimitar el concreto acto de contenido sexual constitutivo de violación cuando se acompañen de violencia o intimidación, a despejar dudas en torno a si las mujeres pueden ser sujetos activos de las mismas, ya tengan como sujeto pasivo a otra mujer o a un hombre ${ }^{36}$. En efecto, la inclusión como modalidades del delito de violación de la introducción de miembros corporales y objetos vía anal o vaginal ha traído consigo aparejado el fin de la discusión en torno a los accesos linguales y digitales podían ser equiparados a la modalidad clásica de introducción del pene a los efectos del delito de violación ${ }^{37}$. Desde algún sector del feminismo se venía reivindicando dicha ampliación, con la que se equiparaban pues los papeles de sujetos activos y pasivos de hombres y mujeres en esta sede. Puede entenderse que, en este contexto, incorporar ahora una previsión específica, en virtud de la cual se agravara la pena si el sujeto activo es el hombre que es o ha sido compañero sentimental con o sin convivencia, parece que no casaba con la objetivización del delito de violación que, por otros caminos, se había alcanzado ${ }^{38}$.

Además, volviendo al catálogo de infracciones penales a las que se refiere el art. I.3 de la LO I/2004, hay que criticar abiertamente el hecho de que el legislador se refiera en vez de a los delitos contra la libertad ambulatoria, a «privaciones arbitrarias de la libertad» ${ }^{39}$, pues eso conduce a mantener una doble vara de medir, en la medida en que parece que se está dando a entender que existen supuestos en los que los hombres están legitimados para privar de libertad a sus mujeres. Aclarado lo anterior, no se entiende muy bien por qué, la LO I/2004 ha elevado a la categoría de delito determinados comportamientos constitutivos hasta ella de faltas de amenazas y de coacciones y sin embargo, no ha procedido a agravar la pena por los mismos motivos en el delito de detenciones ilegales ${ }^{40}$.

En efecto, si se tiene en consideración que desde el punto de vista de la clase de violencia de género a que va referida la LO I/2004, el autor actúa con la finalidad de

\footnotetext{
${ }^{35}$ Todo apunta no obstante, a la incompatibilidad de ambas circunstancias, por violación del principio non bis in idem, en tanto que el marido somete a actos a su esposa, por el hecho de serlo y porque tradicionalmente los hombres han discriminado a sus mujeres.

${ }^{36}$ Sobre la interpretación jurisprudencial española del delito de violación así como sobre el discurso machista de fondo véase: M. CUGAT MAURI, «La ambivalencia de la protección de la libertad sexual. Jurisprudencia del Tribunal Supremo sobre el delito de violación», en Jueces para la Democracia, 20/1993, pp. 76 y Ss. Y sobre la fundamentación de que al día de hoy la prostitución no sea constitutiva de delito, E.R. ZAFFARONI, «El discurso feminista y el poder punitivo», en H. BIRGÍN (compilador), Las trampas del poder punitivo: el género en Derecho penal, Bilbos, Buenos Aires, 2000, p. 29, para el que la prostitución no es más que «una forma de mantener subordinada a la mujer, esclavizada como mercancía de un hombre que la alquila. Esa situación de servidumbre hace innecesaria la intervención controladora del poder punitivo sobre ella»; M.J. CRUZ BLANCA, «Derecho penal y discriminación por razón de sexo. La violencia doméstica en la codificación penal», en L. MORILLAS CUEVA (coord.), Estudios penales sobre violencia doméstica, ed. DIFUSA, Madrid, 2002 pp. 26 y ss; M.L. MAQUEDA ABREU, «Feminismo y prostitución», en El País, I de abril de 2006.
}

${ }^{37}$ F. MORALES PRATS, R. GARCÍA ALBERO, «De las agresiones sexuales», en G. QUINTERO OLIVARES (dir.), F. MORALES PRATS (coord.), Comentarios a la parte especial del Derecho penal, cit., pp. 294 y ss.

${ }^{38}$ Vid. M. ACALE SÁNCHEZ, «Análisis del Código penal en materia de violencia de género contra las mujeres desde una perspectiva transversal», cit., pp. I32 y ss.

${ }^{39}$ Siguiendo en este punto a la definición contenida en la IV Conferencia de Naciones Unidas sobre las mujeres de I995.

${ }^{40}$ J. BOIX REIG, Prólogo, en J. BOIX REIG, E. MARTÍNEZ GARCÍA (coords.), La nueva Ley contra la Violencia de Género, Iustel, Madrid, 2005, p. 22. 
terminar aislando a la mujer de sus contactos, de sumirla en la máxima soledad, momento en el que puede decirse que, perdidos los resortes de amigos, familia, compañeros de trabajo, etc., la mujer está a disposición del autor, no es infrecuente que la prive de libertad, encerrándola o deteniéndola. No obstante, este no es el único motivo que sostiene las críticas que aquí se están realizando: desde un punto de vista puramente dogmático, tampoco puede olvidarse que los delitos de detenciones ilegales entran en concurso de normas con los delitos de amenazas y coacciones leves. Así, no son pocas las sentencias en las que se califican los hechos como constitutivos de detenciones ilegales y posteriormente se castiga por coacciones ${ }^{4 \mathrm{I}}$. La situación es sorprendente en la medida en que se ha agravado especialmente la pena del autor de las coacciones «leves», pero no de quien detenga ilegalmente, si bien es este caso, de nuevo, nada impedirá recurrir a la aplicación del parentesco como circunstancia agravante, lo que determinará la imposición de la pena tipo en su mitad superior (art. 66), a pesar de que en su interior, como se decía, no quepan las relaciones de noviazgo; así mismo, como se señalaba anteriormente, también podrá recurrir a la circunstancia agravante de discriminación en razón de sexo del art. 22.4, cuando se pruebe el móvil discriminatorio.

Finalmente, si la violencia de género comprende todo acto de violencia física o psíquica, ha de subrayarse el hecho de que no se haya modificado la pena de los delitos de homicidio o asesinato, que suponen los actos más graves de la violencia que quiere prevenir la LO I/2004.

Posteriormente se analizará la opinión del Tribunal Constitucional al respecto de la selección por parte del legislador de los concretos delitos que han visto modificadas sus penas en su Sentencia 59/2008, de I4 de mayo.

\section{La reforma no anunciada del delito de quebrantamiento de condena}

Y aunque a él no se hace referencia alguna en el art. I.3 LO I/2004, se ha procedido a reformar el delito de quebrantamiento de condena del art. 468, incluyendo un número 2 en el que establece que «se impondrá en todo caso la pena de prisión de seis meses a un año a los que quebrantaren una pena de las contempladas en el artículo 48 de este Código o una medida cautelar o de seguridad de la misma naturaleza impuestas en procesos criminales en los que el ofendido sea alguna de las personas a las que se refiere el art. 173.2». La finalidad no es otra que asegurarse que en todo caso los jueces tienen que imponer pena de prisión, lo que deja vía libre a la prisión provisional como medida cautelar.

\footnotetext{
${ }^{41}$ Habrá detención ilegal cuando el sujeto pasivo no pueda libremente salir de ese encierro. Así lo entiende entre otras la Sentencia del Tribunal Supremo 487/2002, de 2 I de marzo al afirmar que el delito de detenciones ilegales exige «bien un encierro o internamiento en un lugar del que a la víctima no le es posible salir por sí misma, o bien una detención o inmovilización más o menos duradera, lo que no sucede cuando la persona [...] mantenga sin embargo su libertad deambulatoria, y con ello la posibilidad de trasladarse de un sitio a otro sin ataduras ni encierro alguno». Habrá detenciones ilegales en aquellos supuestos en los que exista una originaria privación de libertad ilegal; en los casos en los que no exista, sino que por su propia voluntad la víctima acceda a ir con el autor, se dificulta la calificación de los mismos como detención (Sentencia del Tribunal Supremo 445/1999, de 23 de marzo), a diferencia del delito de allanamiento de morada en el que como es sabido, caben una u otra forma de atentar contra la intimidad del morador. Sin embargo, si es posible separar dos hechos, por ejemplo, si voluntariamente se reanuda la convivencia en el convencimiento de que las relaciones personales entre cónyuges van a mejorar, y con posterioridad se produce un suceso singular de privación de libertad, no se ve motivo suficiente para no castigar por detenciones ilegales (Sentencia del Tribunal Supremo I006/1996, de I3 de diciembre). El tiempo que dure la privación de libertad también es básico para distinguir las detenciones ilegales de las coacciones, pero sólo en el sentido siguiente: la privación de libertad inmediata e instantánea será constitutiva de coacción. El hecho de que dure más o menos en el tiempo no va a determinar nada, sino que será preciso analizar si atendiendo a los criterios anteriores, puede decirse en sentido estricto que existe una otra forma de atentar contra la libertad ajena. Será pues la casuística, la vía para diferenciar en cada caso concreto uno $\mathrm{u}$ otro atentado contra la libertad.
} 
Son dos las dudas que suscita la reforma del delito de quebrantamiento de condena operada a través de la LO I/2004 $4^{42}$.

Por un lado, si el bien jurídico protegido en su interior es uno de carácter colectivo, que está relacionado con la Administración de justicia ${ }^{43}$, en particular, con la lesión de la efectividad de las resoluciones judiciales, no se alcanza a comprender qué lugar ocupan en el nuevo tipo agravado otros bienes jurídicos de titularidad individual de la persona respecto de la cual el agresor haya quebrantado su condena, medida de seguridad, prisión, medida cautelar, conducción o custodia ${ }^{44}$; el hecho, por ejemplo, de que no pueda imponerse el alejamiento - ni como pena, ni como medida cautelar- como consecuencia de la comisión del delito de quebrantamiento parece venir a corroborar que en su sede no se protegen bienes jurídicos individuales de los que sea titular una víctima en particular. Lo que sí parece quedar claro es que en su interior, vista la extensión del tipo a todas las formas de violencia doméstica, no ocupa ningún lugar el supuesto bien jurídico de carácter colectivo «pertenencia al género femenino históricamente discriminado a manos del masculino», al que posteriormente se aludirá.

En segundo lugar, tampoco se alcanza a comprender que se proceda a reformar el delito examinado en el marco de la $\mathrm{LO}$ I/2004, en la medida en que, como se decía, ésta tiene la finalidad de hacer frente a la violencia que sufren las mujeres a manos de quienes son o han sido sus maridos o compañeros sentimentales, con o sin convivencia, mientras que la reforma operada en materia de quebrantamiento de condena se refiere a los supuestos en los que «el ofendido sea alguna de las personas a las que se refiere el art. 173.2», en el que se incluyen todos los supuestos de violencia doméstica, así como otros casos que por decisión del legislador, se asimilan a aquélla: se dejan pues a un lado, las cuestiones relativas al sexo de los sujetos activos y pasivos, la particular relación familiar que les una, así como la especial vulnerabilidad de la victima y de la convivencia, con tal de que sujeto activo y pasivo puedan ser considerados «familiares» a los efectos del delito de mal trato habitual en dicho ámbito. Por eso se trata de una reforma que no tiene encaje en la sede de la LO I/2004, porque difumina la respuesta penal entre todos los miembros de la unidad familiar y asimilados, mientras que el objetivo de la misma ley ha sido precisamente el de

\footnotetext{
${ }^{42}$ Fuera del ámbito de la LO I/2004, como es sabido, la LO I5/2003 modificó la pena de alejamiento, incorporando un régimen específico en los casos de violencia doméstica, a cuyo tenor, cuando uno de los delitos señalados en el número i del art. 57 se comentan en el ámbito de esta clase de violencia, el juez, en todo caso, ha de imponer la pena de alejamiento en la modalidad de prohibición de aproximarse a la víctima del número 2 del art. 48. Con esto, los problemas que se pueden producir en los casos en los que la mujer víctima de violencia no quiera «alejarse» de su marido son amplios, en la medida en que caso de permita el acercamiento o que incluso sea ella quien lo lleve a cabo, puede estar incurriendo en concepto de cooperadora necesaria o inductora del delito de quebrantamiento de condena cometido por su marido. En este sentido, en opinión de MAQUEDA ABREU («La violencia de género: entre el concepto jurídico y la realidad social», cit., p. Io) llama la atención sobre «la necesidad de tomar en consideración al perspectiva de la mujer, en la idea común de que es incapaz de decidir por sí misma, permitiendo que pase de estar sometida al maltratador a estarlo al Estado». Las cuestiones de inconstitucionalidad que se han planteado en torno al art. 57.2 son muy numerosas. Al día de hoy, el Tribunal Constitucional ha resuelto dos de ellas, a través de las Sentencias I40/2008, de 28 de octubre y I4I/2008, de 30 de octubre; no obstante, si se tiene en consideración el tiempo que se llevaba esperando que el Tribunal resolviera esta cuestión, y que finalmente en ambas Sentencias se concluyen sin entrar en el fondo del asunto por vicios de procedibilidad, no puede extrañar que dejen una agria sensación a quien las estaba esperando.

${ }^{43}$ En opinión de M. COMAS D’ARGEMIR I CENDRA, J. QUERALT JIMÉNEZ («La violencia de género: política criminal y ley penal», en AAVV, Homenaje al Profesor Dr. Gonzalo Rodríguez Mourullo, Thomson-Civitas, Navarra, 2005, p. I.22I) se trata de un delito que protege un bien jurídico plural, pues junto a la Administración de Justicia «desempeña un papel principalísimo la indemnidad de la mujer $y$ de otras víctimas de delito de violencia de género». No obstante, habría que afirmar que o bien se defiende la existencia en todo caso de ese bien jurídico plural o, en todo caso, entender que se protege exclusivamente la Administración de justicia. También defiende que se trata de un delito que protege un bien jurídico plural L. ARROYO ZAPATERO: ver su comparecencia ante la Comisión de Trabajo y Asuntos Sociales del Congreso, Diario de Sesiones, Congreso de los Diputados, Comisiones, núm. 70, 08.09.2004, p. I4. Vid. del mismo autor: «Legitimidad constitucional y conveniencia político-criminal de la Ley contra la violencia de género», cit., pp. 724 y ss.
}

${ }^{44}$ R. GARCÍA ALBERO, «Del quebrantamiento de condena», en G. QUINTERO OLIVARES (dir.), F. MORALES PRATS (coord.), Comentarios a la parte especial del Derecho penal, cit., p. I.835. 
establecer respuestas individuales según la clase de violencia «doméstica» cometida. Si se tiene en cuenta que a la vez que la LO I/2004 incluye la referencia a la «violencia doméstica» en el art. 468.2, la elimina de los artículos 83, 84 y 88 en materia de suspensión y sustitución de las penas privativas de libertad, sustituyéndola por la de «violencia de género», se comprenderá que no se alcancen a comprender los motivos que han llevado al legislador a operar de esta forma.

\section{Visión de género en la LO I/2004 y principio de proporcionalidad extrínseca}

Como se decía, la LO I/2004 ha procedido a elevar las penas para los delitos de lesiones, mal trato, amenazas leves, coacciones leves y quebrantamiento de condena. Ahora bien, hay que tener en consideración que el Código ha de mantener en equilibrio las distintas penas impuestas en atención al conjunto de bienes jurídicos que protege. Por ello, la modificación de unas penas y no del resto, ha provocado el resentimiento del principio de proporcionalidad extrínseca en lo que a la regulación de los delitos de lesiones agravadas, y amenazas y coacciones leves se trata. Basta con comprobar, como se hará a continuación, las penas que les corresponden a los autores de las conductas que rodean a los delitos reformados.

Antes de proceder a ello, ha de subrayarse que sobre esta cuestión ya se ha manifestado el Tribunal Constitucional en su Sentencia 59/2008, de I4 de mayo, y en un doble sentido ${ }^{45}$.

En el primero, para justificar el hecho de que se hayan reformado las penas de delitos menos graves y no de los más graves. En esta línea sentido afirma que los delitos de mal trato habitual, contra la libertad sexual, lesiones graves $\mathrm{u}$ homicidios «al tratarse de delitos de un significado mayor desvalor» tienen asignada una «pena significativamente mayor», es decir, están suficientemente penados. Esta afirmación no puede convencer si se tiene en consideración que aunque efectivamente son delitos más graves y tienen prevista una pena también más grave, lo cierto es que en su interior no se está teniendo en consideración la afección negativa al bien jurídico que supuestamente protegen los tipos penales reformados por la LO I/2004.

Pero además, ha venido a afirmar que, en todo caso, «lo que la argumentación más bien sugiere es o un déficit de protección en los preceptos comparados -lo que supone una especie de desproporción inversa sin, en principio, relevancia constitucional- o una desigualdad por indiferenciación en dichos preceptos merecedora de similar juicio de irrelevancia» ${ }^{46}$. El hecho de que el Tribunal Constitucional entienda que el déficit de protección por desproporción inversa no tiene «en principio, relevancia constitucional», no debe ser motivo suficiente para descalificar la labor del intérprete, y eso sí, parece que debería ser argumento de peso para que el legislador procediera a practicar las reformas legales oportunas para dotar de coherencia interna al Código penal, dado el reconocimiento de falta de competencia esgrimido por el alto Tribunal. A la vista del contenido del Anteproyecto de reforma del Código penal de I4 de noviembre pasado, que actualmente sigue su tramitación parlamentaria $-y$ que no somete a reforma la pena de los delitos de homicidio, ni de asesinato, ni de las lesiones más graves-, parece que el legislador no ha tenido en consideración el aviso que le ha hecho el propio Tribunal Constitucional sobre la desproporción de la respuesta punitiva frente a los fenómenos más graves de la violencia de

\footnotetext{
${ }^{45}$ Sorprendentemente, la STC 45/2009, de I9 de febrero, guarda silencio al respecto.

${ }^{46}$ Un análisis de la jurisprudencia constitucional sobre el principio de constitucionalidad puede verse en el análisis que realiza N.J. DE LA MATA BARRANCO, El principio de proporcionalidad penal, cit., en particular, pp. 29 y ss.
} 
género, que son aquellos que ponen fin a la vida de la víctima. De esta forma, el legislador español tiene una cita pendiente, en la que ha de corregir la desproporción que se ha incorporado en el seno del Código penal por esta vía.

En relación con los delitos objeto de reforma, como se decía, la operada en sede de delitos de lesiones se ha centrado en el art. I48, en el que se encuentran una serie de circunstancias que específicamente agravan la pena del tipo básico del delito de lesiones castigado en el art. I47. Ello determina que si la lesión causada es alguna de las castigadas en los artículos I49 ó I50 (aquellas lesiones que entren dentro de las que provocan la pérdida o la inutilidad de un órgano o miembro principal, o de un sentido, la impotencia, la esterilidad, una grave deformidad, o una grave enfermedad somática o psíquica, o cuando se trate de la pérdida o la inutilidad de un órgano o miembro no principal, o la deformidad), los nuevos criterios de agravación de la pena no surtan ningún efecto específico agravatorio, si no es posible reconducir su mayor desvalor a alguna de las circunstancias agravantes genéricas, aunque en este caso, ya no determinarán la imposición de pena de prisión con una duración específica (de 2 a 5 años), sino la pena establecida en los artículos I49 ó I50, según el caso, en su mitad superior. No deja de resultar paradójico pues que lo que ha querido prevenir el legislador -la violencia de género- le impida agravar las penas de las modalidades más grave de lesiones de los artículos I49 ó I5047. Por ello, si el marido o compañero sentimental le causa a su cónyuge mujer algunas de las lesiones del art. I49 (la ablación del clítoris, o la deformidad, por ejemplo), habrá que recurrir, en su caso, al parentesco como circunstancia que en este caso determinaría la agravación de la responsabilidad criminal ${ }^{48}$, así como a la agravante de discriminación en razón de sexo del art. 22.4.

Por otro lado, si se observa, sólo se agrava la pena cuando la víctima de la lesión sea quien es o ha sido esposa o mujer unida por análoga relación sentimental aún sin convivencia, o la persona especialmente vulnerable que conviva con el autor: se guarda silencio en torno a la agravación de la pena en el resto de casos en los que la víctima sea alguna de las definidas en el art. I73.2 «exceptuadas las contempladas en el apartado anterion. En todos estos casos, la lesión será castiga en atención a lo establecido en el tipo básico del art. I47, en virtud de las reglas de determinación judicial de la pena de los artículos 66 y siguientes.

Además, ha de tenerse en consideración que en sede de lesiones agravadas no se ha previsto la posibilidad de que el juez, atendiendo a las circunstancias personales del autor y las concurrentes en la realización del hecho pueda rebajar en un grado la pena, con lo cual el marco penológico típico será siempre y en todo caso el previsto en el art. I48 (prisión de 2 a 5 años).

Por lo que toca a las modificaciones operadas de los delitos de amenazas, el art. I7I.4 impone pena de «prisión de 6 meses $a 1$ año o de trabajos en beneficio de la comunidad de 31 a 80 días $\gamma$, en todo caso, privación del derecho a la tenencia y porte de armas de 1 año $y 1$ día a 3 años, así como, cuando el Juez o Tribunal lo estime adecuado al interés del menor o incapaz, inhabilitación para el ejercicio de patria potestad, tutela, curatela, guarda o acogimiento hasta 5 años» cuando la ofendida sea o haya sido esposa, o mujer que esté o haya estado ligada a él por una análoga relación de afectividad aun sin convivencia, o cuando la víctima sea una persona especialmente vulnerable que conviva con el autor si se amenaza de forma leve. Si la víctima de la amenaza leve con armas es «alguna de las personas a las que se refiere el art. 173.2, exceptuadas las contempladas en el apartado anteriorn, se impone pena inferior de «prisión de 3 meses a 1 año o trabajos en beneficio de la comunidad de 31 a 80 días $\gamma$, en todo caso,

\footnotetext{
${ }^{47}$ M. ACALE SÁNCHEZ, La discriminación hacia la mujer por razón de género en el Código penal, cit., p. I94.

${ }^{48}$ Agravación de la pena que, en todo caso, quedaría excluida cuando se tratara de personas unidas por análoga relación sentimental al matrimonio pero que no hubieran llegado a convivir, en la medida en que como es sabido, estas relaciones quedan fuera de las fronteras del parentesco a efectos penales.
} 
privación del derecho a la tenencia y porte de armas de 1 a 3 años, así como, cuando el Juez o Tribunal lo estime adecuado al interés del menor o incapaz, inhabilitación especial para el ejercicio de la patria potestad, tutela, curatela, guarda o acogimiento por tiempo de 6 meses a 3 aก̃os».

Con ello, y al no haberse modificado las penas del resto de modalidades de delito de amenazas, se produce un claro solapamiento entre límites mínimos y máximos de unas y otras penas, lo que pone de manifiesto la violación del principio de proporcionalidad extrínseca. En efecto, si se piensa en el supuesto del marido que amenaza a su mujer: si se trata de una amenaza grave de un mal no constitutivo de delito, la pena es de prisión de tres meses a un año o multa de 6 a 24 meses; si por el contrario se trata ya de una amenaza grave de un mal constitutivo de delito, prisión de uno a cinco años si el culpable consigue su propósito, y de prisión de 6 meses a 3 años caso de no haberlo conseguido; si es una amenaza grave no condicional de un mal constitutivo de delito: prisión de 6 meses a 2 años; y, finalmente, cuando se trata de una amenaza leve: prisión de 6 meses a i año o trabajos en beneficio de la comunidad de 30 a 80 días y, en todo caso, privación del derecho a la tenencia y porte de armas de i a 3 años, así como, cuando el juez o tribunal lo estime adecuado al interés del menor o incapaz, inhabilitación especial para el ejercicio de la patria potestad, tutela, curatela, guarda o acogimiento por tiempo de 3 meses a 3 años.

Ello determina que las amenazas más leves vienen castigadas con penas que en abstracto son más graves que las que les corresponden a las modalidades de amenazas más graves y ello aunque en este caso, no haya inconveniente alguno para recurrir a la circunstancia mixta de parentesco con carácter agravante, lo que supone, por un lado, la eliminación de las parejas unidas por análoga efectividad al matrimonio sin convivencia los novios- y la inclusión del resto de relaciones parentales a las que allí se hace referencia, con completa independencia de los sexos de las personas implicadas.

Lamentablemente, el Tribunal Constitucional en su Sentencia 45/2009, de I9 de febrero, no ha tenido en consideración el desajuste comentado.

Y en sede de coacciones, la pena que le corresponde al autor del delito de coacciones leves es de prisión de 6 meses a I año o de trabajos en beneficio de la comunidad de 3I a 80 días y, en todo caso, privación del derecho a la tenencia y porte de armas de i año y i día a 3 años, así como, cuando el Juez o Tribunal lo estime adecuado al interés del menor o incapaz, inhabilitación para el ejercicio de patria potestad, tutela, curatela, guarda o acogimiento hasta 5 años cuando la ofendida sea o haya sido esposa, o mujer que esté o haya estado ligada a él por una análoga relación de afectividad aun sin convivencia, o cuando la víctima sea una persona especialmente vulnerable que conviva con el autor si se le coacciona de modo leve. Si la coacción leve va dirigida a alguna de las personas a las que se refiere el art. I73.2 «exceptuadas las contempladas en el apartado anterior», la pena es de localización permanente de 4 a 8 días, siempre en domicilio diferente y alejado del de la víctima o trabajos en beneficio de la comunidad de 5 a io días. Ahora bien, si la coacción es grave, en atención a lo previsto en el art. I72.I, la pena es de prisión de 6 meses a 3 años o con multa de 12 a 24 meses, según la gravedad de la coacción o de los medios empleados. De nuevo, como se observa, no existe proporción entre la pena a imponer y la gravedad de la coacción ${ }^{49}$. Es decir, si el marido coacciona levemente a su esposa, le corresponde pena «proporcionalmente» superior a la que le corresponde si la

\footnotetext{
${ }^{49}$ Critica LARRAURI (Criminología crítica y violencia de género, cit., p. 43) el hecho de que la LO I/2004 haya procedido a agravar la pena de las coacciones, y sin embargo, «no haya regulado un delito de acecho para castigar específicamente a quien tiene como objetivo controlar e intimidar a la ex pareja precisamente sin violencia». En extenso, sobre esta cuestión, véase: L. DE FAZIO, «Le vittime di stalking», en Modena Group on Stalking, Precosí di aiuto per vittime di stalking, Tipomonza, Milán, 2007.
} 
coacciona gravemente. Ello es tanto como incitar a coaccionar más gravemente ${ }^{50}$.

La situación que se produce en el interior del delito de mal trato presenta también su propia singularidad desde el punto de vista del principio de proporcionalidad extrínseca. Así, si por cualquier medio o procedimiento se causa menoscabo psíquico o una lesión no definidos como delito, o se golpea o maltrata de obra a otro sin causarle lesión, se impone pena de prisión de 6 meses a I año o trabajos en beneficio de la comunidad de 31 a 80 días y, en todo caso, privación del derecho a la tenencia y porte de armas de I año y i día a 3 años, así como, cuando el Juez o Tribunal lo estime adecuado al interés del menor o incapaz, inhabilitación para el ejercicio de patria potestad, tutela, curatela, guarda o acogimiento hasta 5 años cuando la ofendida sea o haya sido esposa, o mujer que esté o haya estado ligada a él por una análoga relación de afectividad aun sin convivencia, o cuando la víctima sea una persona especialmente vulnerable que conviva con el autor ${ }^{\mathrm{I}}$. Y si la víctima es alguna de las personas a que se refiere el art. I73.2 «exceptuadas las personas contempladas en el apartado anterior», la pena es de prisión de 3 meses a I año, o trabajos en beneficio de la comunidad de 3i a 80 y, en todo caso, privación del derecho a la tenencia y porte de armas de I año y I día a 3 años, así como, cuando el Juez o Tribunal lo estime adecuado al interés del menor o incapaz, inhabilitación para el ejercicio de la patria potestad, tutela, curatela, guarda o acogimiento de 6 meses a 3 años. Lo que se quiere destacar en este momento es que si la lesión es constitutiva de delito, entra en aplicación automáticamente la agravante prevista en el número 4 del art. I48, con lo cual, el marco penológico típico se sube a la prisión de 2 a 5 años, respetándose en este caso la graduación punitiva que ha de existir entre infracciones criminales menos (mal trato) y más graves (lesiones). No obstante, ha de resaltarse que se ha alcanzado dicha proporcionalidad extrínseca a base de agravamiento tras agravamiento de la pena, con lo que las claves del debate parece que deben situarse en este caso no ya en la posible violación del principio de proporcionalidad extrínseca, sino más sencillamente, en el simple endurecimiento de la respuesta punitiva y en los límites más generales al ius puniedi del Estado: si no se constata este dato, es fácil legitimar la respuesta actual frente a la violencia de género en el ámbito del delito de mal trato ${ }^{52}$. Ha de tenerse en consideración que en este caso tampoco existe la atenuación facultativa de la pena en atención a las circunstancias del caso o las personales del autor, a las que pudiera acudir el juez en el caso concreto para corregir disparidad penológica alguna, como ocurre en el mal trato, las amenazas o las coacciones.

Todo este desajuste penológico es el que está a la espera de ser corregido por el legislador ya que, si bien el Tribunal Constitucional en las Sentencias en las que se ha detenido a analizar la constitucionalidad del delito de maltrato del art. I53 se ha declarado incompetente para hacerlo, sin duda alguna lo ha dejado subrayado.

\section{Visión de género en la LO I/2004 y principio de proporcionalidad intrínseca}

Al margen ya de la relación analizada en el punto anterior sobre las penas que les corresponden a las nuevas figuras delictivas en comparación a otras penas de los delitos con los que están indudablemente relacionados, el principio de proporcionalidad también somete a examen en sí mismas a las propias conductas castigadas como delito de lesiones

\footnotetext{
${ }^{50}$ M. ACALE SÁNCHEZ, «Análisis del Código penal en materia de violencia de género contra las mujeres desde una perspectiva transversal», cit., p. I39.

${ }^{51}$ Véase: C. VILLACAMPA ESTIARTE, «El maltrato singular cualificado por razón de género. Debate acerca de su constitucionalidad», cit., p. I4.

${ }^{52}$ LARRAURI PIJOAN («Igualdad y violencia de género», cit., p. 8) hace referencia al hecho de que con carácter general «la virtud preventiva de la pena de prisión ha sido generalmente aceptada, por lo que resulta al menos curioso que ahora sea objeto de tanta controversia».
} 
agravadas, mal trato singular, amenazas leves y coacciones también leves, en atención a si las mismas revisten la suficiente gravedad como para ser castigadas penalmente como delito.

Las nuevas figuras constitutivas de delito llegaron al Libro II del Código a distinta velocidad. Así, fue la LO II/2003 la que elevó a dicho lugar las hasta entonces faltas de lesiones del art. 6I7.I, de mal trato del art. 6I7.2 y de amenazas leves del art. 620, cuando los sujetos activos y pasivos fueran algunos de los señalados en el delito de malos tratos habituales en el ámbito familiar del hoy art. I73.2. Por su parte, la LO I/2004 procedió a reformar su contenido, tanto por la inclusión de una diferenciación de la pena según el sexo de los sujetos activos y pasivos así como de la relación que existiera entre ellos, como porque extrajo de su interior la amenaza leve que, con buen criterio, incluyó en el nuevo art. I7I; simultáneamente, aprovechó la ocasión para elevar al ámbito de los delitos, alguna de las modalidades de la falta de coacciones leves, que en 2003 se quedaron olvidadas en el seno del Libro III.

De la exposición de motivos de la LO II/2003 se desprende que la razón por la cual se elevaron estas conductas de falta a delito es puramente pragmática: «poder tratarlas procesalmente como delitos». Lo que no significa que hubieran dejado de ser comportamientos menos graves, desde el punto de vista del principio de ofensividad. Con esto, no es de extrañar por tanto que pronto empezaran los jueces a interponer cuestiones de inconstitucionalidad referidas en primer lugar a la redacción dada al delito de mal trato singular a través de la LO II/2003 y posteriormente, a la que le dio a los delitos de mal trato, amenazas y coacciones (artículos I53, I7I y I72, respectivamente) la LO I/2004 ${ }^{53}$.

En este sentido, no puede olvidarse cuáles son los actos que están siendo castigados como delitos: hematoma (Sentencia de la Audiencia Provincial de Cádiz de 27 de diciembre de 2002), esguince cervical (Sentencia de la Audiencia Provincial de Sevilla de 24 de octubre de 2002), arañazo (Sentencia de la Audiencia Provincial de Sevilla 275/2002, de I2 de junio), bofetada (Sentencia de la Audiencia Provincial de Huelva de 4 de abril de 2002) $-{ }^{54}$, fuerte tirón de orejas (Auto del Juzgado de lo Penal número 4 de Murcia ${ }^{55}$ ) y a la vista de los comportamientos que hasta la aprobación de la LO I/2004 daban lugar a la aplicación de la falta de coacciones leves -cambiar la cerradura de la puerta de la casa de verano (Sentencia de las Audiencias Provinciales de Vizcaya de I7 de noviembre de 2003 y de Girona de i9 de mayo de 2004)-.

En cuanto a la respuesta del Tribunal Constitucional en su Sentencia 59/2008, de I4 de mayo -y toda la cascada de sentencias posteriores que le han sucedido- en torno a la violación del principio de proporcionalidad de la pena en relación con los cánones que ofrecen los principios de igualdad y de culpabilidad, las distintas sentencias que se han referido a él han hecho referencia a los argumentos contenidos en el Auto 233/2004, de 7 de junio ${ }^{56}$, en el que se analizaba la cuestión de inconstitucionalidad presentada por el Juzgado de Instrucción número I de San Vicente de Raspeig en relación con la posible violación del principio de proporcionalidad de la pena prevista en el art. I53 en la redacción que al mismo le dio la LO II/2003 ${ }^{57}$. En ese momento, se utilizaron dos argumentos para ni

\footnotetext{
${ }^{53}$ Véase las que cita en relación con el delito de mal trato singular C. VILLACAMPA ESTIARTE, «El maltrato cualificado por razón de género», cit., pp. 9 y Iо.

${ }^{54} \mathrm{M}$. ACALE SÁNCHEZ, «Los nuevos delitos de mal trato singular y de malos tratos habituales en distintos ámbitos, incluido el familiar», cit., p. 39.

${ }^{55}$ Este Auto es el que ha dado lugar a la STC 59/2008, de I4 de mayo, la primera que ha afirmado la constitucionalidad de la reforma operada por la LO I/2004 en el delito de mal trato singular del art. I53.I.

${ }^{56}$ Véase el comentario que realiza: J.L. RUBIDO DE LA TORRE, Ley de violencia de género. Ajuste de constitucionalidad en materia penal, cit., pp. 74 y ss.

${ }^{57}$ El precepto mencionado establecía en ese momento: «El que por cualquier medio o procedimiento causara a otro menoscabo psíquico o una lesión no definidos como delito en este Código, o golpeara o maltratara de obra a otro sin
} 
si quiera admitir a trámite la cuestión: que el Auto de remisión del juzgado carecía de la más mínima fundamentación, y que no existía la desproporción alegada, en la medida en que el legislador dispuso como pena alternativa a la prisión de 3 meses a I año, la de trabajos en beneficio de la comunidad, de forma que si el juzgador, en el juicio de proporcionalidad que ha realizar en relación con los hechos objeto de enjuiciamiento, entiende que la primera resulta excesiva, siempre puede recurrir a la segunda.

Con esta base, en la resolución de las cuestiones de inconstitucionalidad presentadas sobre la supuesta violación del principio de proporcionalidad en relación con la nueva redacción dada al art. I53 por la LO I/2004, el Tribunal Constitucional, en sus Sentencias 8I y 82/2008, de I7 de julio, 95, 96 y 99/2008, de 24 de julio, ha vuelto a hacer referencia a ese mismo argumento: «a la vista de su poca entidad -tres meses de privación de libertad en el límite inferior de la pena y una pena potestativa de inhabilitación que en el art. 153.1 es superior a dos años en su límite máximo, pero inferior a seis meses en su límite mínimo-, tampoco cabe apreciar que la diferencia de penas de las normas comparadas entrañe una desproporción que conduzca por esta vía a la inconstitucionalidad ex principio de igualdad del artículo cuestionado, máxime si se repara en que esta pena de prisión diferenciada en su límite minimo es alternativa a la pena de trabajos en beneficio de la comunidad, igual en ambos tipos, $y$ en que el art. 153.4 incorpora como opción de adaptación judicial de la pena a las peculiariedades del caso el que la pena del art. 153.1 pueda rebajarse en un grado 'en atención a las circunstancias personales del autor y las concurrentes en la realización del hecho', en previsión ciertamente aplicable también al art. 153.2».

En idénticos términos se ha manifestado últimamente la STC 45/2009, de I9 de febrero, al afirmar la constitucionalidad del delito de amenazas leves del art. I7I.4, a pesar de que en este caso, las diferencias de tratamiento penal y penológico de las amenazas son mayores que en el mal trato pues aquí se trata de que la amenaza leve sin armas que profiere el varón hacia la mujer con la que está o estuvo casado o unido sentimentalmente con o sin convivencia- es, en todo caso, constitutiva de delito y se castiga con pena de «prisión de 6 meses a 1 año o trabajos en beneficio de la comunidad de 31 a 80 días, $\gamma$, en todo caso, privación del derecho a la tenencia y porte de armas de 1 a 3 años, así como, cuando el Juez o Tribunal lo estime adecuado al interés del menor o incapaz, inhabilitación especial para el ejercicio de la patria potestad, tutela, curatela, guarda o acogimiento por tiempo de 6 meses a 3 años», mientras que cuando el sujeto activo de la misma amenaza leve es mujer, la conducta es constitutiva de mera falta y castigada en atención a lo dispuesto en el art. 620 , con pena de localización permanente de 4 a 8 días o trabajos en beneficio de la comunidad de 5 a io días. Como afirma uno de los votos particulares de la Sentencia, quizás «en el caso del art. 171.4, objeto de las cuestiones de inconstitucionalidad acumuladas en este caso, la cuestión es aún más aguda, porque no se trata de una pena mayor para un mismos hecho, según se cometa por la mujer, o por el hombre, sino de que esa misma conducta en un caso constituye falta y en el otro delito, lo que, aparte de otras consideraciones respecto a que de por medio está el empleo de armas, hubiera exigido una mayor ponderación respecto a la proporcionalidad $y$ la igualdad, $y$ en todo caso, una interpretación conforme expresa, llevada al Fallo» ${ }^{5}$.

En este punto han de puntualizarse varias cuestiones.

causarle lesión, o amenazara a otro de modo leve con armas $y$ otros instrumentos peligrosos, cuando en todos estos casos el ofendido fuera alguna de las personas a las que se refiere el art. 173.2, será castigado con la pena de prisión de tres meses a un año o trabajos en beneficio de la comunidad de 31 a 80 días $\gamma$, en todo caso, privación del derecho a la tenencia y porte de armas de uno a tres años, así como, cuando el juez o tribunal lo estime adecuado al interés del menor o incapaz, inhabilitación especial para el ejercicio de la patria potestad, tutela, curatela, guarda o acogimiento por tiempo de seis meses a tres años.

Se impondrán las penas en su mitad superior cuando el delito se perpetre en presencia de menores, o utilizando armas, o tenga lugar en el domicilio común o en el domicilio de la víctima, o se realicen quebrantando una pena de las contempladas en el art. 48 de este Código o una medida cautelar o de seguridad de la misma naturaleza».

${ }^{58}$ Voto particular que presenta el Magistrado Rodríguez Arribas. 
En primer lugar, como se ha señalado anteriormente en relación con la STC 59/2008, de I4 de mayo, la violación del principio de proporcionalidad se produce no sólo en relación con los concretos hechos castigados ahora como delito, sino en comparación con la pena que dispone el Código para el autor de otras conductas más graves (lesiones, por ejemplo) que están castigadas con pena igual o inferior ${ }^{59}$.

En segundo, no se puede dejar en manos del juez que corrija la desproporcionalidad consagrada por el legislador a no ser que se estén transfiriendo potestades que competen al poder legislativo al judicial: el aplicador del derecho, en virtud de las reglas de determinación judicial de la pena -artículos 66 y siguientes- determinará dentro del marco penal típico la concreta pena a imponer pero siempre y cuando el legislador haya respetado dicho principio a la hora de realizar el principio de proporcionalidad abstracto (esto es, en el momento de la concreta incriminación). Si el juicio abstracto de proporcionalidad no es correcto, tampoco puede serlo el que realice el juez; para justificar éste solo señala la importancia de los bienes jurídicos a proteger y la necesidad social de elevar la pena: el fundamento democrático del Derecho penal no puede permitir que se violen los principios básicos del Derecho penal.

Pero en tercer lugar, olvida el Tribunal Constitucional que la pena de trabajos en beneficio de la comunidad es una pena que sólo admite ser impuesta si se obtiene el consentimiento del penado. De esta forma, si en el caso concreto el juez entiende que es desproporcionada la imposición de una pena de prisión y el penado no consiente el cumplimiento de la pena de trabajos en beneficio de la comunidad, tendrá que imponer una pena desproporcionada en abstracto, pero también en concreto, atendiendo a las concretas circunstancias del caso. Siempre podría recurrir a través del sistema de sustitución de la pena de prisión por la multa, si no fuera porque expresamente el art. 88 lo impide en los casos de la violencia de género: ahora bien, se insiste, la aplicación de todos estos mecanismos de elección de penas alternativas o de imposición de penas sustituyentes ha de partir de una determinación legal de la pena proporcionada; cosa que en este caso no existe.

Por otro lado, como ya se señalaba anteriormente, tamaña violación del principio de proporcionalidad puede provocar -como afirma GONZALEZ RUS- «paradójicamente, efectos indeseables, pues lo desmesurado de la respuesta penal puede generar una cierta reluctancia en juzgados $y$ tribunales a imponer penas tan desproporcionadas, buscando subterfugios $y$ abriendo agujeros que acaben vaciando el tipo penal» ${ }^{60}$.

Pero además, en atención a la pena compacta que impone el legislador en estos supuestos, y respecto a las penas de prisión nótese que a pesar de tener idéntico límite máximo -I año-, los mínimos son distintos: sorprende que dichas penas de prisión tengan como alternativa idéntica pena de trabajo en beneficio de la comunidad con idéntica duración -de 3I a 80-. Parece a todas luces que o bien el legislador ha querido simplemente utilizar la pena de prisión como mera amenaza, o bien que la regla de la proporcionalidad no ha sido respetada en este caso, pues la pena de prisión de mayor duración debería llevar como alternativa otra pena de mayor duración o, a la inversa, la pena de prisión de menor duración debió llevar asociada como alternativa los trabajos en beneficio de la comunidad de menor duración.

El mismo razonamiento habría que realizar en relación con la pena de privación del derecho a la tenencia y porte de armas: en el segundo caso debió tener una duración

\footnotetext{
${ }^{59}$ Vid. supra.

${ }^{60}$ J.J. GONZÁLEZ RUS, «Las lesiones», en M. COBO DEL ROSAL, Derecho penal español. Parte especial, ed. Dykinson, Madrid, 2005, p. I58. Junto al principio de proporcionalidad, en opinión de A. ASÚA BATARRITA («Los nuevos delitos de violencia doméstica tras la Reforma de la LO II/2003, de 29 de septiembre», en Cuadernos penales José María Lidón, I/2004, p. 223) también se viola el de adecuación.
} 
inferior a la primera, pues la conducta es menos grave. Y sin embargo, en los dos supuestos la duración es la misma: I año y I día a 3 años ${ }^{6 \mathrm{I}}$. «En todo caso», señala el art. I53, ya se imponga la prisión o los trabajos en beneficio de la comunidad, y ya se trate de sus números Iffl o $2 \mathrm{ffl}$, se impondrá también la pena de privación del derecho a la tenencia y porte de armas de I a 3 años, ello además con independencia de que el autor causara menoscabo psíquico o una lesión no definida como delito con o sin arma, golpeara o maltratara de obra a otro con o sin ellas, o amenazara de modo leves con armas $y$ otros instrumentos peligrosos.

Respecto a la imposición de la pena de inhabilitación para el ejercicio de la patria potestad, tutela, curatela, guarda o acogimiento hasta cinco años en el número iffl y de 6 meses a 3 años en el número 2 ffl, en atención «al interés del menor o incapaz» ha de tenerse en consideración -además de que sólo podrá ser impuesta si el sujeto pasivo está sometido a ellas- que el legislador se ha olvidado que junto de los menores e incapaces, también se incluyen ahora en el art. I53 por remisión al art. I73.2 otras personas que están unidas al agresor por vínculos distintos a los familiares ${ }^{62}$. Así, por ejemplo, en el caso de mal trato singular a persona interna en una residencia geriátrica no se ha previsto la imposición de la pena de inhabilitación para el ejercicio de la profesión, oficio o cargo como pena principal ${ }^{63}$ si bien podrá recurrirse a ella como pena accesoria según lo establecido en el art. ${ }^{6} 6$ con todo lo que ello conlleva, pues si la ejecución de la pena principal queda en suspenso, la lógica impone que también quede en dicho estado la pena accesoria y además, su duración será la misma de la pena de prisión principal y, por tanto, de 3 meses a I año, siendo así que como pena principal la inhabilitación para el ejercicio de la patria potestad cuando de menores e incapaces se trate, tiene una duración de 6 meses a 3 años y su ejecución es independiente del estado en el que se encuentre la pena principal ${ }^{64}$ : a igual gravedad de la conducta, igual debió ser también la consecuencia jurídica prevista en atención al principio de proporcionalidad ${ }^{65}$. El problema más importante que se plantea en este caso es que la pena de inhabilitación se impone en ambos casos, y además que tiene mayor duración en el primero que en el segundo, siendo así que en el primero se trata de mujer víctima de violencia a manos de quien sea o haya sido su marido o compañero sentimental.

Finalmente, ha de tenerse en consideración que aunque se distinga el límite mínimo de las penas de prisión a imponer según quien sea la víctima, la ejecución de ambas penas puede quedar en suspenso, si bien, como se señalaba anteriormente, en el caso de los delitos relacionados con la «violencia de género» el juez, al decretarla, deberá decretar también obligatoriamente la sumisión del penado a las prohibiciones de acudir a determinados lugares, o de aproximarse a la víctima, o a aquellos de sus familiares $u$ otras personas que determine el juez o tribunal, o de comunicarse con ellos así como a participar

\footnotetext{
${ }^{61}$ Esta privación fue muy bien recibida por todos los colectivos que informaron el Proyecto de la hoy LO II/2003 con independencia de que en estos casos se utilicen las manos y no otros instrumentos peligrosos. Véase el Informe del Consejo General del Poder Judicial sobre el Anteproyecto de Ley Orgánica de medidas concretas en materia de Seguridad Ciudadana, Violencia Doméstica e Integración Social de los Extranjeros; Informe de la Fiscalía General del Estado sobre el Anteproyecto de Ley Orgánica de medidas concretas en materia de Seguridad Ciudadana, Violencia Doméstica e Integración Social de los Extranjeros, este informe puede consultarse en www.fiscalia.org.

${ }^{62}$ En el mismo sentido, P. LAURENZO COPELLO, «Los nuevos delitos de violencia doméstica: otra reforma precipitada», en F. PÉREZ ÁLVAREZ (dir.), Serta in memoriam Alexandri Baratta, ed. Servicio de Publicaciones de la Universidad de Salamanca, Salamanca, p. 830.

${ }^{63}$ Así lo resaltaba la Fiscalía General del Estado en su Informe sobre el Anteproyecto de Ley Orgánica de medidas concretas en materia de Seguridad Ciudadana, Violencia Doméstica e Integración Social de los Extranjeros.

${ }^{64}$ M. ACALE SÁNCHEZ, El delito de malos tratos físicos Y psíquicos en el ámbito familiar, cit., p. 200.

${ }^{65}$ El propio Consejo General del Poder Judicial ya destacaba la violación del principio de proporcionalidad en relación con esta nueva figura delictiva en su Informe sobre el Anteproyecto de Ley Orgánica de medidas concretas en materia de Seguridad Ciudadana, Violencia Doméstica e Integración Social de los Extranjeros. En el mismo sentido, la Fiscalía General del Estado en su Informe sobre el Anteproyecto de Ley Orgánica de Medidas concretas en Materia de Seguridad Ciudadana, Violencia Doméstica e Integración Social de los Extranjeros.
} 
en programas formativos, según señala el art. 83.I in fine, cuando se trate del resto de supuestos de violencia doméstica, al suspender la ejecución, el juez decidirá en atención a la peligrosidad criminal y a si el culpable tiene o no otros procedimientos penales abiertos si le somete o no a esas o a otras pautas de comportamiento ${ }^{66}$.

En todo caso, el endurecimiento de la respuesta punitiva no se produce sólo por la agravación de la pena a imponer, sino porque se trata de conductas, que sin que se haya producido un cambio en torno a su gravedad, sino simplemente con la finalidad de poder tratarlas procesalmente como delito, han perdido su condición de faltas. Y son muchas, las diferencias que existen entre unas y otras infracciones criminales. Así, como señala el Auto del Juzgado de lo Penal núm. I de Murcia 547/2005, 3 de agosto -en el que se plantea una cuestión de inconstitucionalidad sobre la nueva regulación de las amenazas- hay que tener en consideración que la calificación como meras faltas, impide la inscripción del «antecedente» en el Registro de Penados y Rebeldes, su comisión no provoca la suspensión previamente concedida por otro delito, no da lugar en el futuro a la apreciación de la agravante de reincidencia, la determinación de la pena no se somete a las pautas establecidas en los artículos 66 y siguientes (art. $638 \mathrm{CP}$ ), el plazo de suspensión de la pena en caso de concederse es inferior a si se califica como delito, las penas accesorias del art. 57 son potestativas y no son imponibles penas accesorias del art. 56 , el régimen de medidas cautelares es muy distinto pues no cabe apreciar la prisión provisional. A ello añade que «la condena en costas, incluso cuando se haya tramitado la causa como si se tratase de delito, si la calificación en sentencia es de falta, no incluirá los honorarios de profesionales, cuya intervención no es necesaria» ${ }^{67}$. Son muchas pues las diferencias a justificar. En particular, piénsese en las modificaciones operadas en sede de coacciones leves: no todas ellas son constitutivas de delito, con lo cual, habrá algunas que tengan el tratamiento penal de un delito y otras de mera falta penal (por ejemplo, coacción leve de la esposa sobre su marido que no es especialmente vulnerable, a pesar de que sigan viviendo juntos, o coacción sobre el marido en los casos en los que ya no exista convivencia).

La STC 45/2009, de I9 de febrero se ha manifestado expresamente en torno a estos otros efectos diferenciales de la respuesta punitiva según se trate de un delito o de una falta. En este sentido se limita a afirmar que «a pesar de esta notable diferencia punitiva entre las amenazas leves sin armas en los casos que el legislador denomina como propios de violencia de género (los del art. 171.4, párrafo 1ffl) y el resto de las amenazas leves sin armas que puedan darse en el seno de la pareja, no consideramos que dicha diferencia convierta en inconstitucional ex art. 14 el precepto cuestionado por la desproporción de las consecuencias de una diferenciación que en sí ya hemos calificada de razonable. Conviene recordar una vez más que es éste un juicio de constitucionalidad, que es el único que nos compete, y que el mismo nada dice acerca de la oportunidad de la norma ni de su calidad, ni siquiera en términos de axiología constitucional», volviendo a continuación a basarse en la importancia del bien jurídico protegido, así como en la posibilidad de que el juez en el caso concreto y en el momento de determinación de la pena, acuda a la pena alternativa de los trabajos en beneficio de la comunidad o la rebaje en un grado en atención a las circunstancias personales del autor y las concurrentes en la realización del hecho. Con todo, parece que si la diferencia punitiva es ajustada a la Constitución, sólo queda afirmar en el sentido mantenido en el texto que el mal trato

\footnotetext{
${ }^{66}$ Vid infra.

${ }^{67}$ Además afirma que «sólo en relación con la pena de prisión, o respecto de los delitos de los artículos 153 Y 173.2 $C P$, es posible la imposición de condiciones adicionales a la suspensión, según el art. $83 C P »$ : en este caso sin embargo, se debería haber afirmado que por definición, las faltas no están castigadas con la pena de prisión, por lo que en caso de que se proceda a la suspensión de la pena de localización permanente de las faltas o de arresto sustitutorio por impago de multa, como únicas penas privativas de libertad que cabe imponer como consecuencia de la comisión de una falta, no van a llevar aparejada la imposición de pautas de comportamiento del art. 83, que se limitan conceptualmente a los supuestos en los que se haya impuesto pena de prisión. Estos mismos argumentos son reproducidos en el Auto del Juzgado de lo Penal núm. 43, 305/2005, de 29 de julio, por el que se plantea cuestión de inconstitucionalidad en relación con el art. I53.I tras la redacción que al mismo le ha dado la LO I/2004.
} 
cometido sobre la víctima que no sea una persona especialmente vulnerable que conviva con el autor, no debería ser constitutivo de delito, sino también de mera falta. No se sabe bien si con ello, el Tribunal Constitucional está sugiriendo -al autorizarle- al legislador que conduzca la conducta castigada en el número 2 del art. I53 al Titulo III del Código.

\section{Visión de género en la LO I/2004 y el efecto de la desigual protección

\author{
VII.I La falta de tratamiento homogéneo del resto de víctimas de la violencia \\ doméstica
}

Aun admitiendo la mayor, esto es, la legitimación de las reformas operadas por la LO I/2004, las nuevas figuras delictivas tratan de forma desigual a las víctimas de la violencia doméstica según se trate de mal trato, amenazas o coacciones, sin que se siga un criterio o principio definidor: simplemente, como efectos colaterales de la defectuosa reforma operada por la LO I/2004. Nótese como por un lado, la respuesta ante las lesiones, mal trato, amenazas y coacciones cuando la víctima es la mujer que está o estuvo casada o unida sentimentalmente al agresor con o sin convivencia, así como cuando se trate de personas especialmente vulnerables que convivan con el autor, es compacta -es más: la pena es la misma-, por otro, las otras víctimas de la violencia doméstica no reciben una respuesta idéntica, sino que ha de estarse al concreto delito cometido. Con ello, no se trata solo de constatar que las penas a imponer según los sujetos activos y pasivos sean distintas, sino además que cuando se trata de la respuesta frente a la violencia doméstica (dentro de la que se incluye la de la mujer sobre el hombre o la mujer que es o ha sido su esposo o esposa, si la víctima no es una persona especialmente vulnerable que conviva con aquélla), no existe un trato penológico idéntico, poniendo de manifiesto que la equiparación valorativa que se hace respecto a un grupo, desaparece cuando la víctima pertenece al otro.

Así, en el seno del delito de lesiones agravadas del art. I48, el pertenecer al núcleo amplio de la unidad familiar no da lugar a la agravación de la pena, por lo que las lesiones que se les cause a cualquiera de ellos o son castigadas por el tipo básico del art. I47 (con pena de prisión de seis meses a tres años), o lo son en atención de alguno de los otros criterios de agravación de la pena específicos - pero genéricos-incluidos en el art. I48, o, finalmente, se recurre al catálogo de agravantes genérico del art. 22 o a la circunstancia mixta de parentesco, teniendo en consideración en este caso, que muchas de las clases de violencias domésticas a las que se refiere el art. I73.2 no pueden dar lugar a la apreciación del parentesco porque sencillamente, no se trata de parientes ni siquiera a efectos penales.

Cuando de maltrato singular se trata, nótese como el art. I53 determina la imposición de la misma pena a quien someta a dicha conducta a la mujer que es o ha sido esposa o compañera sentimental del agresor con o sin convivencia, que si se trata de persona especialmente vulnerable que conviva con el autor. Si por el contrario, la víctima pertenece al resto de la familia, a igualdad de hecho, la pena es inferior: prisión de 3 meses a I año o de trabajos en beneficio de la comunidad de 3i a 80 días y, en todo caso, privación del derecho a la tenencia y porte de armas de i año y i día a 3 años, así como, cuando el Juez o Tribunal lo estime adecuado al interés del menor o incapaz, inhabilitación para el ejercicio de patria potestad, tutela, curatela, guarda o acogimiento de 6 meses a 3 años. Ahora bien: cuando la víctima no sea ninguna de las señaladas con anterioridad, la conducta es castigada con pena de localización permanente de 6 a i2 días o multa de i a 2 meses si se causa a otro una lesión no definida como delito, como falta del art. 6I7.I, o pena 
de 2 a 6 días de localización permanente o multa de io a 30 días si se «golpea o maltrata a otro sin causarle lesión», como falta de mal trato de obra del art. 6I7.2 ${ }^{68}$.

Si se lleva a cabo ahora un análisis similar del delito de amenazas leves, las conclusiones son distintas: a mayor gravedad objetiva de la conducta, se impone menor pena. En efecto, el número 4 castiga al hombre que amenace de modo leve a quien sea o haya sido su esposa o compañera sentimental, aún sin convivencia, así como a quien amenace a persona especialmente vulnerable que conviva con el autor; la pena -en ambos casos- es la misma que la establecida en el art. $153^{69}$. Por su parte, el número 5 castiga a quien «de modo leve amenace con armas $u$ otros instrumentos peligrosos» a algunas de las personas a las que se refiere el artículo I73.2, exceptuadas las contempladas en el apartado anterior de este artículo; en este caso, la pena es inferior ${ }^{70}$. Por su parte, la falta de amenazas del art. 620 seguirá siendo de aplicación en aquellos supuestos en los que se lleven a cabo amenazas leves sin armas sobre las personas especialmente vulnerables que no convivan con el autor o sobre las personas que no sean especialmente vulnerables pero que convivan con el autor dentro de las que quedan referenciadas en el art. i73.2. Cuestión ésta que ya ha sido analizada y reafirmada por el Tribunal Constitucional en su Sentencia 45/2009, de I9 de febrero, como se veía anteriormente.

La posible violación del principio de igualdad ante la ley se multiplica cuando se analizan las reformas operadas en el ámbito de las coacciones. En efecto, el número $2 \mathrm{ffl}$ del art. I72 impone la misma pena que los artículos I53 y I7I.4, al hombre que «coaccione de forma leve» a la mujer que sea o haya sido su esposa o compañera sentimental, aún sin convivencia, así como al que coaccione de modo leve a una persona especialmente vulnerable que conviva con el autor. Si por el contrario se coacciona de forma leve a cualquier otro miembro de la unidad familiar en los términos establecidos en el art. I73.2, la conducta ya no es constitutiva de delito (como ocurre en materia de mal trato y amenazas) sino que hay que recurrir en todo caso a la falta del art. 620 en la que se establece una pena especial para estos supuestos: localización permanente de 4 a 8 días, siempre en domicilio diferente y alejado del de la víctima, o trabajos en beneficio de la comunidad de 5 a io días.

En definitiva, parece que la idéntica significación material de la conducta constitutiva de mal trato, amenazas leves o coacciones leves, no puede dar lugar a un tratamiento homogéneo (en cuanto que se impone en todos los casos un misma pena) cuando el autor es el varón y la víctima la mujer con la que está o estuvo casado o unido

\footnotetext{
${ }^{68}$ Véase: C. VILLACAMPA ESTIARTE, «El maltrato singular cualificado por razón de género. Debate acerca de su constitucionalidad», cit., pp. 4 y ss.

${ }^{69}$ Prisión de seis meses a un año o trabajos en beneficio de la comunidad de 3I a 80 días y, en todo caso, privación del derecho a la tenencia y porte de armas de i año y i día a 3 años, así como, cuando el juez o tribunal lo estime adecuado al interés del menor o incapaz, inhabilitación para el ejercicio de la patria potestad, tutela, curatela, guarda o acogimiento de hasta cinco años.

${ }^{70}$ Prisión de 3 meses a I año o de trabajos en beneficio de la comunidad de 3I a 80 días, y en todo caso, privación del derecho a la tenencia y porte de armas de un año y un día a tres años, así como cuando el juez o tribunal lo estime adecuado al interés del menor o incapaz, inhabilitación para el ejercicio de patria potestad, tutela, curatela, guarda o acogimiento de seis meses a tres años. Auto del Juzgado núm. I de Murcia 54/2005, de 3 de agosto de 2005 concluye su análisis sobre la violación del principio de proporcionalidad en relación con las reformas operadas en el ámbito de las amenazas a través de la LO I/2004 afirmando que «siguiendo con el esquema de análisis apuntado por la doctrina constitucionalista debe reconocerse, en definitiva, que el bien jurídico protegido es lo suficientemente relevante para justificar una sanción, incluso una sanción penal, pero, dado el carácter circunstancial de las amenazas y la existencia de zonas limítrofes con la irrelevancia jurídica, sólo la previsión de una respuesta penal extraordinariamente flexible permite encontrar la sanción proporcionada a cada caso, lo cual es especialmente cierto en relación con las amenazas leves sin uso de armas o instrumentos peligrosos. Y en este punto, ya en relación con un juicio de proporcionalidad estricto, se plantean las dudas de constitucionalidad del precepto, en la medida en que ese régimen razonablemente flexible se entiende vulnerado al hacer desaparecer, en determinadas relaciones, la posible calificación como falta de la conducta, exigencia que no se suple con la precisión de alternativas a la privación de libertad en el art. 171.4 o con la posibilidad de atenuación prevista en el art. 171.6, pues las consecuencias jurídicas de la calificación como delito o falta... son mucho más dramáticas que las que derivan de la dosificación concreta de la pena en relación con uno u otro tipo de infracción».
} 
sentimentalmente, llegaran o no a convivir y, sin embargo, cuando la víctima no es esa persona especialmente vulnerable que conviva con el autor, a pesar de estar incluida dentro del art. I73.2 se diversifique el tratamiento penal, pues según el caso, la conducta es constitutiva de delito o falta y además que se impongan penas distintas. De ahí se deriva la posible violación del principio de igualdad de tratamiento penal cuando se trata de víctimas de la violencia doméstica no de género definida en el art. I de la LO I/2004.

\section{VII.2 El supuesto de las agresiones mutuas}

La primera cuestión a la que se ha de hacer referencia es qué se entiende por tales agresiones: así, se agreden mutuamente un hombre y una mujer cuando en un mismo momento ambos se propinan golpes, insultos, etc. ${ }^{71}$. Caso de que entre ambos no exista convivencia, el mal trato del hombre sería castigado como delito de mal trato del art. I53.I con pena de prisión de 6 meses a I año y la mujer, al no existir convivencia, sería castigada con pena de prisión de 3 meses a I año. Pero incluso en el caso de que ésta existiera, sería necesario además probar la especial vulnerabilidad de la víctima para aplicarle la misma pena que al hombre. Mayor diferencia penológica habría si en vez de maltratarse, los cónyuges se coaccionan mutuamente, en la medida en que el hombre sería castigado con la pena de prisión de 6 meses a I año, y la mujer, como autora de una falta de vejaciones, con la pena de localización permanente de 4 a 8 días o trabajos en beneficio de la comunidad de 5 a Io días ${ }^{72}$.

Esta cuestión ya ha sido analizada por la Sentencia de la Audiencia Provincial de Barcelona de I4 de noviembre de 2005 en relación con el delito de mal trato singular -pero cuyo razonamiento se puede extrapolar sin mayor problema a las coacciones y a las amenazas-; en ella se entiende que cuando de riñas mutuas se trate, no es aplicable el art. I53.I, partiendo de que esta clase de violencias requiere «ser instrumento de discriminación, dominación o subyugación de alguno de los sujetos que comprende» y en la medida en que entiende que no se trata más que de una riña entre dos personas adultas en igualdad de condiciones y sin que ninguna de ellas se encuentre en una posición inferior a la de la otra parte en la contienda, «deberá limitarse a la falta de lesiones, al maltrato o a la amenaza que definen los artículos $6_{17}$ y $6_{20} C_{\gg{ }^{73}}$. Si bien la intención del juzgador ha sido la de someter a una lectura restrictiva la nueva regulación, nada hubiera impedido la absurda solución de castigarlos con distintas penas, es más, según la definición del art. I de la LO I/2004, ésta debió ser la solución en la medida en que durante su tramitación parlamentaria se eliminó del art. I la referencia que se hacía a que la violencia sobre la mujer era la «utilizada como instrumento para mantener la discriminación, la desigualdad y las relaciones de poder de los hombres sobre las mujeres», bastando desde entonces que se trate de una violencia que sea «manifestación de la discriminación, la situación de desigualdad y las relaciones de poder de los hombres sobre las mujeres», hombres y mujeres, en este caso, entendidos como colectivos, no como el concreto hombre que somete a una concreta mujer a este tipo de actuaciones.

${ }^{7 \pi}$ Los supuestos que comenta LARRAURI PIJOAN («Igualdad y violencia de género», cit., p. I2), efectivamente son supuestos muy distintos a los que ahora se hace referencia.

${ }^{72}$ Como consecuencia del hecho de que la LO I/2004 no haya elevado al ámbito de los delitos de coacciones leves, la que se lleve a cabo sobre el resto de los miembros de la unidad familiar, que al día de hoy sigue siendo una conducta que no es más que una falta, se castiga en atención a lo dispuesto en el art. 620. Y esta es una de las cuestiones sobre las que se espera una sentencia «distinta» a las habidas hasta este momento por parte del Tribunal Constitucional porque quizás una «desproporción manifiesta», «un desequilibrio patente $y$ excesivo o irrazonable... a partir de las pautas axiológicas constitucionalmente indiscutibles $y$ de su concreción en la propia actividad legislativa», según establece la propia STC 59/2008, de I4 de mayo.

${ }^{73}$ En el mismo sentido, entiende LARRAURI PIJOAN («Igualdad y violencia de género», cit., p. I4) que en el interior del art. I53 «existe un elemento del tipo implícito -la existencia de un contexto de dominación- que la acusación debe probar que concurre», aclarando a posteriori que lo que ha de probarse es que «la agresión se produce en un 'contexto de dominación' o tiene por finalidad establecer un control general coercitivo». 
Otra de las vías utilizadas por la jurisprudencia para hacer frente a las agresiones mutuas, como se señala en el Auto del Juzgado número 6 de Madrid de i4 de febrero de $2006^{74}$, es calificar el maltrato del hombre hacia la mujer como mal trato típico a los efectos del número I del art. I53, y el cometido por la mujer contra el hombre a través del número 2 del mismo artículo pero imponer en ambos casos la misma pena de trabajos en beneficio de la comunidad que, como se decía, tiene la misma duración. Pero por esta vía, se puede encontrar el juzgador con el inconveniente de que uno de los condenados -o los dos- no acepte el cumplimiento de dicha pena, con lo cual, debería recurrir a la pena privativa de libertad de 6 meses para el hombre y 3 meses para la mujer. Cierto es que incluso en este caso puede recurrir a la atenuación facultativa de la pena del número 3 del art. I53, pero al hacerlo, vendrá obligado a aplicársela a ambos condenados, de forma que debería terminar imponiendo a ambos penas de prisión de distinta duración en el tiempo por la realización de la misma conducta.

Ahora bien, de razonamientos como estos, que intentan salir del callejón al que les ha conducido la LO I/2004, se ha alejado el Tribunal Constitucional cuando parcularizadamente analiza esta cuestión en su Sentencia 96/2008, de 24 de julio ${ }^{75}$, en la medida en que lejos de reclamar ningún elemento subjetivo específico en el actuar del hombre, se limita a afirmar efectivamente, que ambas bofetadas tienen una distinta valoración por parte del legislador en virtud de los bienes jurídicos que se lesionan en uno y en otro caso, más plurales cuando la víctima es la mujer que el hombre. Con ello, está afirmando que la pena agravada es de automática aplicación en todo caso $^{76}$, con independencia de la especial vulnerabilidad de la concreta mujer, y de la concreta situación en la que se produzcan dichos hechos, poniendo de manifiesto que se trata de ofrecer una respuesta compacta frente a un fenómeno criminal también compacto. De esta forma, si la intención del autor fue la discriminar a la mujer o no por el hecho de serlo, deja de tener papel alguno en el injusto; pero tampoco, como se verá a continuación, en la culpabilidad. Con lo cual, la dignidad de la mujer como persona se puede resentir, pues se presume su especial vulnerabilidad.

Finalmente, también el Tribunal Constitucional ha tenido ya ocasión de pronunciarse, si quiera sea parcialmente en torno a la nueva redacción dada a los delitos y faltas de coacciones a través de la LO I/2004, si bien, se ha desaprovechado la ocasión de entrar si quiera tangencialmente en el fondo del asunto. En efecto, en su Auto 136/2006, de 4 de abril, resuelve la cuestión de inconstitucionalidad planteada por el Juzgado de Instrucción núm. 24 de Madrid, de I6 de diciembre de 2005, aunque no la admite por resultar notoriamente infundada. Ciertamente, es compleja la construcción de la cuestión de inconstitucionalidad que hace el juzgado de Madrid, pues en resumen, plantea una cuestión de inconstitucionalidad por violación del principio de proporcionalidad a la inversa: en efecto, se trataba de una mujer que fue castigada como autora de una falta de coacciones leves del art. 620.2 de la que sujeto pasivo era su marido, esto es, la misma conducta que, si se hubieran invertido los sexos de los sujetos implicados hubiera dado lugar a aplicar el nuevo art. I72.2. La cuestión de inconstitucionalidad centra su fundamentación en que «castigar una misma acción (coaccionar) en todo caso y siempre como delito si se realiza sobre una persona de sexo (femenino) y como falta, si es del sexo contrario

\footnotetext{
${ }^{74}$ Que es el que da lugar a la Sentencia del Tribunal Constitucional 96/2008, de 24 de julio.

${ }^{75}$ Curiosamente, el Tribunal Constitucional ha guardado silencio en torno a las amenazas leves mutuas entre el varón y la mujer que están o estuvieron casados o unidos sentimentalmente, a pesar de que en la cuestión de inconstitucionalidad a la que supuestamente se responde, se planteó la cuestión.

${ }^{76}$ Es interesante comentar la situación que da lugar a que se interponga por parte del Juzgado número 6 de Madrid la cuestión de inconstitucionalidad de I4 de febrero de 2006. Se trata de un supuesto de agresiones mutuas entre un hombre y una mujer miembros de una misma pareja; por lo común, se afirma que cada vez que surge un supuesto de malos tratos mutuos, desde el juzgado se impone a ambos la pena de trabajos en beneficio de la comunidad con la misma duración; sin embargo, en el caso de autos, se da la circunstancia de que cada una de las partes se conformaron con la pena que les pedía el fiscal, mayor para el hombre que para la mujer. Y ante la situación, el juzgado decide plantear la cuestión de inconstitucionalidad.
} 
(masculino), es discriminatorio, $y$ contrario al principio de igualdad del art. 14 de la Constitución». Nótese como lo que en este caso se pretende es que dicha conducta sea castigada por el art. I72.2 como delito de coacción leve, no que se viole el principio de proporcionalidad por haber elevado a delito determinados comportamientos que hasta la aprobación de la LO I/2004 no podían ser considerados más que como faltas del art. 620 . El Tribunal Constitucional la rechaza - con buen criterio- en virtud de la propia esencia de las cuestiones de inconstitucionalidad: «conviene recordar que la cuestión de inconstitucionalidad es un mecanismo de control concreto de constitucionalidad $y$ que tiene que versar sobre un precepto legal concreto de cuya aplicación dependa el fallo que hayan de pronunciar los órganos judiciales... este tipo de razonamiento es más propio de un control abstracto de constitucionalidad que de uno concreto, como el que ahora nos ocupa». Habrá que esperar pues a una nueva oportunidad para que el Tribunal Constitucional se manifieste sobre la constitucionalidad de la nueva regulación de los delitos y faltas de coacciones que, como se decía, es la más defectuosa de todas las reformas que ha operado en el Código penal la LO I/2004.

\section{Visión de género en la LO I/2004 y principio de ofensividad}

El Tribunal Constitucional en su Sentencia 59/2008, de I4 de mayo, así como todas las que le han seguido en el tiempo, ha venido a afirmar que la distinta regulación legal del delito de mal trato, en el que se impone más pena por la realización de idéntica conducta al hombre que maltrate a la mujer que es o ha sido su esposa o compañera sentimental -llegaran o no a convivir- que en otros casos, es susceptible de ser interpretado en clave constitucional, pues cabe hacer una lectura de la letra de la ley que deje a salvo el principio de igualdad, así como el de culpabilidad. En idénticos términos se ha expresado la Sentencia del mismo Tribunal 45/2009, de ig de febrero en relación al delito de amenazas leves. Ahora bien: tanto en uno como en otro caso, se tiene en consideración el contexto en el que se sitúan las agresiones del hombre sobre la mujer, de forma que comparar individualmente la gravedad de dos malos tratos - uno cometido por un hombre, y otro por una mujer, tengan o no a una mujer o a un hombre como sujeto pasivo- desde el punto de vista de la ofensividad de la conducta, así como desde el otro de la culpabilidad del autor, conduciría a error, pues es el contexto lo que viene a legitimar la distinta respuesta punitiva. De dicho contexto relacional se extrae el bien jurídico protegido ${ }^{77}$, según esta interpretación constitucional.

Antes de pasar a analizar este razonamiento es necesario resaltar que, por tres veces, a lo largo de toda la sentencia 59/2008, de I4 de mayo, el Tribunal Constitucional califica como «intolerable» la violencia que sufre la mujer en el ámbito de las relaciones de pareja. Con ello, quizás se olvida que no se le pregunta si es o no «tolerable» dicho fenómeno, en eso se está completamente de acuerdo: lo que se le pregunta es si es o no «constitucional». Y su respuesta, en este punto, no es tan clara, ni tan rotunda, en la medida en que entiende que no es su misión suplir la «competencia exclusiva del legislador», dada la legitimidad democrática de éste, por lo que «nuestro análisis actual del art. 153.1 no puede serlo de su eficacia y bondad, ni alcanza a calibrar el grado de desvalor de su comportamiento típico o el de severidad de la sanción. Sólo nos compete enjuiciar si se han respetado los límites externos que el principio de igualdad impone desde la Constitución la intervención legislativa» ${ }^{78}$. A pesar de que

${ }^{77}$ En el mismo sentido, L. ARROYO ZAPATERO, «Legitimidad constitucional y conveniencia políticocriminal de la Ley contra la violencia de género», cit., p. 725.

\footnotetext{
${ }^{78}$ Esta misma idea se repite posteriormente cuando se vuelve a afirmar que «nuestro análisis relativo a la adecuación constitucional del art. 153.1 CP desde la perspectiva del art. 14 de la Constitución ha de comenzar recordando que la duda se refiere a la selección legislativa de una determinada conducta para su consideración como delictiva con una determinada pena, y que esta labor constituye una competencia exclusiva del legislador para la que goza, dentro de los límites establecidos en la Constitución, de un amplio margen de libertad que deriva de su posición constitucional $\gamma$, en última instancia, de su específica legitimidad democrática».
} 
pueda parecer obvio que sólo al legislador compete la elaboración del catálogo de bienes jurídicos a proteger y la sanción de los mismos, olvida el Tribunal Constitucional que en un Estado social y democrático de derecho, aunque la elaboración de las normas corresponde al poder legislador que ostenta la base democrática, se trata además de un estado de «derecho» y lo que se le ha preguntado al órgano encargado de garantizar la constitucionalidad de las normas que forman parte del ordenamiento jurídico es precisamente si se ajusta o no a «derecho» la respuesta ofrecida por el legislador en la reforma operada por la LO I/2004 del Código penal ${ }^{79}$. Semejante escrupuloso «respeto» del Tribunal Constitucional con la base democrática del poder legislativo, choca no obstante con la situación que se produce cada vez que a través de una sentencia «ordinaria», declara la inconstitucionalidad de una norma, pues en este caso, sin duda alguna, funciona como un legislador en negativo.

Afirma la Sentencia que para evitar la violación del principio de igualdad es preciso demostrar que la situación de desigualdad legal obedece a un «fin discernible $y$ legítimo»; que además se articule la respuesta «en términos no inconsistentes con tal finalidad» y que no se incurra en «desproporción manifiesta». En este punto, lo que interesa es resaltar la identificación del bien jurídico que lleva a cabo el legislador ${ }^{80}$.

El «fin discernible y legítimo» no es otro que hacer frente a la violencia de género en el ámbito de las relaciones de pareja. En este sentido afirma que «no constituye el sexo de los sujetos activos $y$ pasivos $y$ un factor exclusivo o determinante de los tratamiento diferenciados... La diferencia normativa la sustenta el legislador en su voluntad de sancionar más unas agresiones que entiende que son más graves $y$ más reprochables socialmente a partir del contexto relacional en el que se producen $y$ a partir también de que tales conductas no son otra cosa, como a continuación se razonará, que el trasunto de una desigualdad en el ámbito de las relaciones de pareja de gravisimas consecuencias para quien de un modo constitucionalmente intolerable ostenta una posición subordinada». En esta línea sigue afirmando que «cabe considerar que esta inserción supone una mayor lesividad para la víctima: de un lado, para su seguridad, con la disminución de las expectativas futuras de indemnidad, con el temor a ser de nuevo agredida; de otro, para su libertad, para la libre conformación de su voluntad, porque la consolidación de la discriminación agresiva del varón hacia la mujer en el ámbito de la pareja añade un efecto intimidatorio a la conducta, que restringe las posibilidades de actuación libre de la víctima; y además para su dignidad, en cuanto negadora de igual condición de persona y en tanto que hace más perceptible ante la sociedad un menosprecio que la identifica con el grupo menospreciado. No resulta irrazonable entender, en suma, que en la agresión del varón hacia la mujer que es o fue su pareja se ve peculiarmente dañada la libertad de ésta; se ve intensificado su sometimiento a la voluntad del agresor $y$ se ve peculiarmente dañada su dignidad, en cuanto persona agredida el amparo de una arraigada estructura desigualitaria que la considera inferior, como ser con menores competencias, capacidades $y$ derechos a los que cualquier persona merece». Recordando que se trata de castigar un tipo de violencia que es «manifestación de la discriminación, la situación de desigualdad y las relaciones de poder de los hombres sobre las mujeres. En la opción legislativa ahora cuestionada, esta inserción de la conducta agresiva le dota de una violencia peculiar y es, correlativamente, peculiarmente lesiva para la víctima. Y esta gravedad mayor exige una mayor sanción que redunde en una mayor protección de las potenciales víctimas» ${ }^{8 \mathrm{1}}$.

\footnotetext{
${ }^{79}$ No es ésta sin embargo la única sentencia en la que el Tribunal Constitucional que es el poder legislativo el que tiene que entrar a analizar la proporcionalidad entre la conducta y su sanción: es más, esta afirmación es constante en la jurisprudencia constitucional. Véase el análisis que realiza sobre el principio de proporcionalidad en la jurisprudencia del Tribunal Constitucional N.J. DE LA MATA BARRANCO, El principio de proporcionalidad penal, cit., pp. 29 y ss.

so Posteriormente se analizará las referencias contenidas en la Sentencia comentada al principio de culpabilidad.

${ }^{81}$ En términos similares, se manifiesta dentro de la doctrina P. LAURENZO COPELLO, «La violencia de género en la Ley integral. Valoración político criminal», cit., pp. 4 y ss; P. FARALDO CABANA, «Razones para la introducción de la perspectiva de género en Derecho penal a través de la Ley Orgánica I/2004, de 28 de diciembre, sobre medidas de protección integral contra la violencia de género», en Revista Penal, I7/2006, pp. 90 y ss.
} 
Con esto, no puede desconocerse la importancia que tiene el contexto social en el que se han producido en el pasado y se producen en la actualidad este tipo de agresiones, así como tampoco puede desconocerse que autor y víctima, se encuentran incluidos en unos concretos colectivos: el de quienes históricamente discriminan a las mujeres, y el de quienes históricamente sufren las agresiones de aquéllos. En esta línea parece no ser descabellada la siguiente afirmación: el plus de pena se justificaría por la «pertenencia al género femenino históricamente discriminado a manos del masculino ${ }^{\text {"82 }}$, que es un bien jurídico de exclusiva titularidad femenina ${ }^{8_{3}}$. Este es el «grupo menospreciado» al que se refiere la STC 59/2007, de I4 de mayo, desde donde habría que deducir quién es el grupo menospreciante: el formado por los hombres, o lo que parece ser lo mismo, el género masculino, que es el «culpable» de la situación en la que se encuentra aquél.

Visto cuál es el bien jurídico protegido, pasa el Tribunal a analizar si la diferenciación penológica se articula «en términos no inconsistentes con tal finalidad». Y en este sentido afirma que la mayor pena para el hombre obedece a la «mayor necesidad objetiva de protección de determinados bienes de las mujeres en relación con determinadas conductas delictivas. Tal necesidad la muestran las altísimas cifras en torno a la frecuencia de una grave criminalidad que tiene por víctima a la mujer y por agente a la persona que es o fue su pareja. Esa frecuencia constituye un primer aval de razonabilidad de la estrategia penal del legislador de tratar de compensar esta lesividad con la mayor prevención que pueda procurar una elevación de la pena».

Semejante bien jurídico puede traer consigo una serie de efectos secundarios que, quizás podrían hacer que se repensara su inclusión en el Código penal ${ }^{84}$, pues son demasiadas las presunciones iuris et de iure las que allí se hacen.

La primera de ellas consiste en que la protección de semejante bien jurídico se lleva a cabo, presumiendo que todas las mujeres, desde el momento en el que establecen relaciones sentimentales con los hombres, son más vulnerables que éstos. En efecto, puede comprenderse como el Tribunal Constitucional deja sentado que el sexo de los sujetos activos y pasivos es «causa» de la mayor ofensividad de la conducta, no mero factor que incremente el riesgo ${ }^{85}$ y lo presume en todo caso. El legislador ha levantado la LO I/2004 partiendo del dato objetivable en los índices estadísticos de que el hecho de ser mujer es «causa» de mayor vulnerabilidad. Distinta hubiera sido la situación si se hubiera relegado al ámbito de las circunstancias modificativas de la responsabilidad criminal la apreciación o no del móvil discriminatorio, pues en este caso, sólo entraría en aplicación cuando efectivamente el agresor actuara movido por sus ideales machistas. Pero no ha sido así, obviamente $^{86}$.

\footnotetext{
${ }^{82}$ M. ACALE SÁNCHEZ, La discriminación hacia la mujer en razón de género en el Código penal, cit., pp. I5I y SS.

${ }^{8}$ P. LAURENZO COPELLO, «La violencia de género en la Ley integral. Valoración político criminal», cit., pp. 4 y sS; P. FARALDO CABANA, «Razones para la introducción de la perspectiva de género en Derecho penal a través de la Ley Orgánica I/2004, de 28 de diciembre, sobre medidas de protección integral contra la violencia de género», en Revista Penal, I7/2006, pp. 90.

${ }^{84}$ En extenso, véase: M. ACALE SÁNCHEZ, La discriminación hacia la mujer por razón de género en el Código penal, cit., pp. I49 y ss. En el mismo sentido, M. MAQUEDA ABREU, «La violencia de género: entre el concepto jurídico y la realidad social», cit., p. I3.

${ }^{85}$ Como ha afirmado LARRAURI PIJOAN («Igualdad y violencia de género», cit., p. I3). No obstante, de ser mero factor, el Tribunal Constitucional debería haber admitido la prueba de la situación concreta, cosa que no ha hecho.

${ }^{86}$ En el mismo sentido que la Sentencia comentada se manifestó antes FARALDO CABANA («Razones para la introducción de la perspectiva de género en Derecho penal a través de la Ley Orgánica I/2004, de 28 de diciembre, sobre medidas de protección integral contra la violencia de género», cit., p. 90), al afirmar que se protege «la mayor necesidad de protección de la víctima debida no a una supuesta debilidad física o vulnerabilidad innata, sino al efectivo $y$ real desvalimiento construido socialmente a través de la educación, de la religión, de la política... en fin, a través de la imposición de roles familiares tradicionales», a lo que añade que no se trata de
} 
En este punto afirma LARRAURI PIJOAN que no se trata de que el Tribunal Constitucional haya consagrado la inferioridad de la mujer, sino su mayor vulnerabilidad ${ }^{87}$ : no obstante, si la mayor vulnerabilidad de la mujer es tan amplia debido a la propia relación de pareja es que no es «igual» al hombre: es más vulnerable, con lo cual, se está consagrando que la mujer es inferior al hombre, y una respuesta a la violación del principio de culpabilidad, porque de nada sirve responder a una supuesta violación de tal principio asumiendo la mayor: esto es, la mayor gravedad de la violencia del género masculino sobre el femenino.

Ello supone afirmar que la víctima de estas conductas no sería ya la concreta mujer que ha sufrido en sus carnes los actos de violencia, sino el género femenino y que autor del delito no sería ya el hombre que en particular ha llevado a cabo los actos constitutivos de delito, sino todo el género masculino. Con ello, se sobrepasa la perspectiva de la responsabilidad individual que como es sabido es la que se liquida en el ámbito penal. Y se consagra a su vez una segunda presunción iuris et de iure: la pertenencia al género femenino determina la mayor vulnerabilidad de las mujeres, lo que justifica la ultra protección ${ }^{88}$.

Por otro lado, no se entiende por qué el bien jurídico colectivo sólo se menoscaba cuando se llevan a cabo los concretos delitos cuyas penas se han visto agravadas y no en otros casos en los que el resultado producido es más grave: resulta un tanto cuestionable que el género femenino se lesione sólo cuando se causa una lesión del art. I48 o un mal trato sin lesión del art. I53, o cuando levemente se amenaza con causar la muerte, y no cuando se mata a la concreta mujer históricamente objeto de violencia. Quizás en el proceso de selección de las concretas conductas que han visto sus penas agravadas se está poniendo de manifiesto que el legislador pensó en el riesgo de que tras unas amenazas o un mal trato leve, se produjera posteriormente un atentado contra la integridad física o la vida de esa concreta mujer descontextualizada del histórico momento que le ha tocado vivir. Esto es, no se trataría más que de meras presunciones legales, de sospechas, de que en otra ocasión puede llegar a matar a la mujer. Pero los delitos de sospecha en un Estado social y democrático de derecho -que en lo penal se traduce en el principio del Derecho penal de hecho- han de quedar proscritos. Parece pues que se trata de delitos que requieren que la víctima quede con vida para poder presumir que en un futuro el autor puede repetir sus actos e incluso aumentar la gravedad de los mismos, contra esa víctima o contra cualquiera otra que reúna los requisitos de sexo y de «estado civil» (por este motivo, y no por otro, no ha procedido el legislador a incluir una agravación dentro del delito de homicidio similar a que ha incluido en los delitos reformados por la LO I/2004, en la medida en que una vez muerta ya la víctima, no existirá riesgo de que vuelva a ser víctima de ese agresor).

Todo lo anterior conduce a afirmar que el bien jurídico pertenencia al género femenino históricamente subyugado a manos del género masculino no puede ser admitido en un ordenamiento jurídico que parta del principio de ofensividad $-\mathrm{y}$ de culpabilidad, como se verá a continuación-, en la medida en que estaría sosteniendo el desvalor de acción en el mero hecho de pertenecer al género masculino el autor, con lo que estaría afirmando que se trata de un supuesto de responsabilidad puramente objetiva y, a la vez, desde el punto de vista del desvalor de resultado, se trataría de proteger un bien jurídico de carácter supra individual, que puede terminar olvidándose de la concreta víctima que en un

proteger -más- a la mujer por «el mero dato biológico de su sexo, sino por la peculiar situación de inferioridad socialmente construida en que se encuentra cuando el hombre con el que está o ha estado vinculada sentimentalmente ejerce violencia sobre ella aprovechando la superioridad que la relación en su caso le proporciona».

${ }^{87}$ E. LARRAURI PIJOAN, «Igualdad y violencia de género», cit., p. I2.

${ }^{88}$ M.L. MAQUEDA ABREU, «La violencia de género: entre el concepto jurídico y la realidad social», cit., p. IO. 
determinado momento es víctima de violencia a manos de su marido o de su compañero sentimental $^{89}$.

Ha de señalarse que la mayor prevención no se alcanza simplemente con la elevación -simbólica ${ }^{90}$ - de la pena, entre otras cosas porque el Tribunal Constitucional parece que confunde la «mayor prevención» con la «mayor intimidación». En este sentido, quizás haya que volver la vista a BECCARIA al año en I763 y a su razonamiento en torno a que no intimida más la pena más grave, sino aquella otra que, por la eficacia de la actuación policial y por la rapidez de los órganos jurisdiccionales a la hora de impartir justicia se sabe de implacable cumplimiento ${ }^{91,92}$. El hecho de que el Tribunal Constitucional ni siquiera ha prestado atención al dato de que todavía no se haya llevado a cabo la reforma prevista en la disposición final quinta de la LO I/2004, en la que se establece que «en el plazo de seis meses desde la aprobación de esta Ley, procederá a la modificación del artículo 116.4 del Real Decreto 190/1996, de 9 de febrero, por el que se aprueba el Reglamento Penitenciario, estableciendo la obligatoriedad para la Administración Penitenciaria de realizar los programas específicos de tratamiento para internos a que se refiere la presente Ley»" ${ }^{93}$, puede estar poniendo de manifiesto que más que a la prevención, se ha prestado atención al puro castigo, olvidando que tan necesaria es la prevención general, como la especial, y en este segundo caso, sobre todo de aquellas personas que se encuentran ya privadas de libertad por la comisión de un delito de semejante naturaleza. A ello habría que añadir también la lentitud de las reformas reclamadas por la LO I/2004 en el ámbito educativo.

\section{Visión de género en la LO I/2004 y principio de culpabilidad}

Todavía, después de analizar que desde el punto de vista de la construcción del tipo de injusto no existe violación alguna del principio de igualdad en atención al bien jurídico delimitado, pasa a responder el Tribunal Constitucional las dos dudas planteadas en la cuestión de inconstitucionalidad en torno a la posible vulneración del principio de culpabilidad: si existe una presunción legislativa de que en las agresiones del hombre sobre la mujer concurre una intención discriminatoria o un abuso de superioridad, o una situación de vulnerabilidad de la víctima; y si no se está además liquidando la responsabilidad no del concreto autor individual, sino más bien que se trataría de una «responsabilidad colectiva del varón como representante o heredero del grupo opresor». De forma muy escueta responde el Tribunal Constitucional a ambas aseveraciones, aunque en su respuesta no puede desvincularse del concreto bien jurídico que ha delimitado previamente: de ahí que parece que se admite una construcción interactiva del principio de culpabilidad.

\footnotetext{
${ }^{89}$ M. ACALE SÁNCHEZ, La discriminación hacia la mujer en razón de género en el Código penal, cit., pp. I63 y SS.

$9^{\circ} \mathrm{P}$. LAURENZO COPELLO, «La violencia de género en la Ley integral. Valoración político criminal», cit., p. 2I (en página siguiente la autora insiste en la «ola de fascinación por el Derecho penal» que invade a la sociedad actual como forma de acabar con todo conflicto social); M.L. MAQUEDA ABREU, «La violencia de género: entre el concepto jurídico y la realidad social», cit., p. II.

${ }^{91}$ C. BECCARIA, De los delitos y las penas, ed. Altaya, Madrid, I994, p. 6r: «he dicho que la prontitud de la pena es más útil porque cuanto es menor la distancia del tiempo que pasa entre la pena $y$ el delito, tanto es más fuerte $Y$ durable en el ámbito la asociación de estos ideas delito y pena».

${ }^{92}$ Como se afirmaba anteriormente, respecto a la última variable que conforma el principio de igualdad, esto es, la de no incurrir en desproporción manifiesta afirma que «sólo incurriría en desproporción constitucionalmente reprochable ex principio de igualdad entre las consecuencias de los supuestos diferenciados cuando quepa apreciar entre ellos un desequilibrio patente $y$ excesivo o irrazonable... a partir de las pautas axiológicas constitucionalmente indiscutibles $y$ de su concreción en la propia actividad legislativa». Vid. supra.

${ }^{93}$ Vid. P. LAURENZO COPELLO, «La violencia de género en la Ley integral. Valoración político criminal», cit., p. 9 .
} 
A la primera de las alegaciones hechas en la cuestión de inconstitucionalidad no contesta. Se limita a repetir algo que le ha servido para analizar el plus de pena desde el punto de vista del bien jurídico protegido «el legislador no presume un mayor desvalor en la conducta descrita de los varones... Lo que hace el legislador, y lo justifica razonablemente, es apreciar el mayor desvalor y mayor gravedad propios de las conductas descritas en relación con la que tipifica el apartado siguiente. No se trata de una presunción normativa de lesividad, sino de la constatación razonable de tal lesividad a partir de las características de la conducta descrita $\gamma$, entre ellas, la de su significado objetivo como reproducción de un arraigado modelo agresivo de conducta contra la mujer por parte del varón en el ámbito de la pareja».

Respecto a si se trata de una responsabilidad de carácter colectivo, afirma que «en los casos cuestionados que tipifica el art. 153.1 CP el legislador haya apreciado razonablemente un desvalor añadido, porque el autor inserta su conducta en una pauta cultural generadora de gravísimos daños a sus víctimas y porque dota así a su acción de una violencia mucho mayor que la que su acto objetivamente expresa, no comporta que se esté sancionando al sujeto activo de la conducta por las agresiones cometidas por otros cónyuges varones, sino por el especial desvalor de su propia Y personal conducta: por la consciente inserción de aquélla en una concreta estructura social a la que, además, el mismo, y solo él, coadyuva con su violenta acción». De ahí deduce que no se trata de castigar de una muestra de Derecho penal de autor.

Bastaría con intentar hacer abstracción por un momento del contexto: como valorar asépticamente la cachetada que da una persona a otra: no habría más posibilidad que atender a los concretos hechos realizados. Como esto no es sostenible en el conjunto de la sentencia del Tribunal Constitucional, porque necesariamente ha de salir a relucir el contexto social en el que se produce, es fácil comprender que no se trata de liquidar una responsabilidad puramente individual, sino de liquidar la responsabilidad de un sujeto por realizar unos hechos que se producen en un contexto en el que históricamente los hombres han sometido a actos de violencia a sus mujeres. De ahí que las sospechas de violación del principio de culpabilidad sigan en el aire, a pesar de la sentencia ${ }^{94}$.

Estando así las cosas, todo apunta a que cada vez que un hombre históricamente «maltrate» a su cónyuge femenino, tendrá que responder por los concretos comportamientos que haya llevado a cabo (lesiones, coacciones, mal trato, amenaza) de los que es su autor, pero además se le hará «cargar» sobre sus espaldas el peso de la historia, esto es, se le hará responder por todas las culpas del género masculino que ha sometido durante años al género femenino, a modo de una especie de responsabilidad de carácter objetivo puramente moralizante y ejemplificadora, que sólo encontraría respuesta en el marco de un Derecho penal basado en las características de un autor -hombre- que pertenece al género que ha subyugado al otro ${ }^{95}$.

En el ámbito penal el problema que en particular se plantea es que en la medida en que es una rama del ordenamiento jurídico que parte de la responsabilidad personal, no puede tener en consideración más que al concreto autor de la particular conducta constitutiva de delito ${ }^{96}$. Además ha de tenerse en consideración que el Derecho penal es una rama del ordenamiento jurídico que parte de la responsabilidad individual, y no admite en sentido alguno la responsabilidad de carácter colectivo pues no cabe duda que la LO I/2004 está teniendo en consideración la situación en la que históricamente se ha encontrado el género femenino, a consecuencia de la discriminación que hacia ella ha operado el género masculino, pues de forma contraria, se estará haciendo responsable penalmente agravándole la pena- al hombre que someta a actos de violencia a su mujer por los actos

${ }^{94}$ Entiende que se viola el principio de culpabilidad, o en su terminología, el principio de «responsabilidad penal personal» E. GIMBERNAT ORDEIG, Prólogo, cit., p. 22.

${ }^{95}$ M. ACALE SÁNCHEZ, La discriminación hacia la mujer por razón de género en el Código penal, cit., p. I69.

${ }^{96}$ Por todos, vid. J.M. TERRADILLOS BASOCO, Peligrosidad social $Y$ Estado de derecho, ed. Akal, Madrid, I98I, p. 28 y ss. 
que en un determinado momento histórico ha realizado, pero también por los actos que muchos hombres han venido realizando históricamente sobre las mujeres.

El Tribunal Constitucional en su Sentencia I50/I99I, de 4 de julio analizó las características de un derecho penal de la culpabilidad consagrado por la Constitución frente a otro de autor que estaría proscrito en nuestro ordenamiento jurídico. En ella se establece que «no sería constitucionalmente legítimo un derecho penal de autor' que determinara las penas en atención a la personalidad del reo y no según la culpabilidad de éste en la comisión de los hechos». Se parte pues de la necesidad de constatar el principio de culpabilidad en relación con los concretos hechos realizados por el autor. En la misma línea incide la STS 34/2003, de 22 de enero en la que se afirma que «la existencia de anteriores condenas por hechos semejantes o diferentes, no puede ser tenido en consideración por ningún órgano juzgador, como prueba reveladora de la comisión de un hecho delictivo, pues si lo hacemos entraríamos en un derecho penal de autor, plenamente superado e incompatible con el espiritu de la Constitución $y$ sus valores fundamentales». A ello añade la STS 934/I999, de 8 de junio como característica de la culpabilidad la necesidad de que ésta sea entendida en todo caso como «una entidad modificable y que hay hechos posteriores al delito que pueden modificar su significación originaria respecto a la pena aplicable. Todo lo contrario ocurriría si el nuestro fuera un derecho penal de autor, dado que desde esta perspectiva el carácter de autor no puede ser modificado ni compensado, tal como sucede con su tendencia al delito».

Lo anterior sirve pues para caracterizar al derecho penal de la culpabilidad frente al derecho penal de autor en virtud de los siguientes datos: las penas han de ser determinadas en función de los hechos cometidos; la existencia de hechos realizados con anterioridad por el mismo sujeto no pueden servir para conformar el juicio de culpabilidad sobre un hecho posterior, menos aún si los hechos anteriores no han sido cometidos por el autor; y, en tercer lugar, la culpabilidad no puede venir dada pues necesariamente ha de ser entendida en un sentido dinámico, que se adapte a las características del caso concreto. A sensu contrario, un derecho penal de autor se caracteriza porque las penas vienen determinadas en función de la personalidad del autor; los hechos anteriores cometidos por ese mismo sujeto sirven para conformar el juicio de autoría sobre un hecho posterior y finalmente, la culpabilidad viene dada, en el sentido de que no admite parangón.

La respuesta que en este punto ha dado el Tribunal Constitucional en relación a la constitucionalidad de las reformas operadas la LO I/2004 no ha contestado a todas estas cuestiones.

\section{$\mathrm{X}$. Valoración y perspectivas}

La reforma operada por la LO I/2004, no ha sido pacífica; pero tampoco lo ha sido la STC 59/2008, de I4 de mayo -ni lo será con el tiempo la 45/2009, de ig de febrero-, en las que para garantizar su constitucionalidad, el alto Tribunal se ha tenido que emplear a fondo, recurriendo a la destreza de un brillante cirujano que disecciona un cuerpo vivo. Las dudas en torno a dicho precepto siguen abiertas a pesar de que ya se haya afirmado que una de las interpretaciones posibles del mismo es inconstitucional, es decir, aquella que basa en el distinto sexo de los sujetos activos y pasivos la diferencia punitiva. Y que es, en todo caso, el bien jurídico delimitado en el contexto social e histórico de la violencia que sufren las mujeres en las relaciones de pareja, es lo que justifica el distinto trato: con todo lo que ello conlleva.

La cuestión que verdaderamente ha de ser resuelta es si esta sexualización legal del problema de la violencia que sufren las mujeres a manos de los hombres con los que están o han estado unidas sentimentalmente es eficaz para acabar con ella. Nótese que se corre el 
riesgo de utilizar el Código penal de forma puramente simbólica ${ }^{97}$ para proteger al colectivo de mujeres o para sancionar al colectivo de hombres, consagrando otra vez el papel de víctima de la mujer y el de agresor del hombre, esto es, los tradicionales papeles pasivo y activo que la estructura patriarcal ha conferido a mujeres y hombres respectivamente a lo largo de la historia; ello supondría que el feminismo actual no ha encontrado otra vía para alcanzar la igualdad entre hombres y mujeres, que el que tradicionalmente ha encontrado el comportamiento machista para someter a las mujeres, reconociendo pues en todo caso como premisa que el hombre es superior a la mujer.

Desde esta perspectiva, habría que concluir el análisis afirmando que la introducción de los nuevos tipos penales carece de fundamento sólido que los sostenga; que las presunciones que allí se hacen, vuelven a poner de manifiesto la inferioridad real de la mujer respecto al hombre, y que el endurecimiento de la pena no es una forma idónea para sacar a la mujer del lastre cultural que durante generaciones ha tenido -y sigue teniendoque soportar; el recurso al endurecimiento de la pena para acabar con el machismo imperante en la sociedad es una tentativa completamente inidónea por falta de idoneidad del instrumento utilizado para ello: el Derecho penal ${ }^{98}$.

Al final de todo este proceso, queda pues un bien jurídico discutible de titularidad exclusivamente femenina -la pertenencia al género femenino históricamente discriminado a manos del masculino- al coste de presumir, por un lado que todas las mujeres por el hecho de serlo y de establecer una relación sentimental con un hombre son (o se convierten) en inferiores a éstos, y que todos los hombres comulgan con un desprecio absoluto hacia las mujeres, pues en todo caso se les va a imponer la pena superior y no van a ser titulares de aquel bien jurídico. Desde esta perspectiva, no parece que se haya abierto un camino adecuado para acabar con el intolerable problema de la violencia que sufre la mujer en el ámbito de la pareja, cuando se extrae de la titularidad del bien jurídico a los hombres, por el hecho de serlo.

Todavía queda la esperanza de que el Tribunal Constitucional, en las próximas sentencias que ha de hacer públicas en relación con los delitos de coacciones y lesiones agravadas tenga por lo menos en consideración que existen motivos específicos en cada uno de ellos como para individualizar su respuesta.

\section{\% Bibliografía}

ACALE SÁNCHEZ, M., «El artículo primero de la Ley Orgánica I/2004, de 28 de diciembre, de protección integral contra la violencia de género: el concepto de violencia de género», en P. FARALDO CABANA (dira.), Política criminal y reformas penales, ed. Tirant lo Blanch, Valencia, 2007.

ACALE SÁNCHEZ, M., «Los nuevos delitos de mal trato singular y de malos tratos habituales en distintos ámbitos, incluido el familiar», en Revista de Derecho penal y Criminología, I5/2005.

ACALE SÁNCHEZ, M., El delito de malos tratos físicos y psíquicos en el ámbito familiar, ed. Tirant lo Blanch, Valencia, 2000.

ACALE SÁNCHEZ, M., La discriminación hacia la mujer por razón de género en el Código penal, ed. Reus, Madrid, 2006.

ACALE SÁNCHEZ, M., «Análisis del Código penal en materia de violencia de género contra las mujeres desde una perspectiva transversal», en C. VILLACAMPA ESTIARTE (coorda.), Violencia de género y sistema de justicia penal, ed. Tirant lo Blanch, Valencia, 2008. IO.

${ }^{97}$ P. LAURENZO COPELLO, «La violencia de género en la Ley integral. Valoración político-criminal», cit., p.

${ }_{98}^{98}$ M. ACALE SÁNCHEZ, La discriminación hacia la mujer en razón de género en el Código penal, cit., pp. 4I2. 
ACALE SÁNCHEZ, M., «Del Código penal de la Democracia al Código penal de la seguridad», en F. PÉREZ ÁLVAREZ (ed.), Serta In memoriam Alexandri Baratta, ed. Universidad de Salamanca, Salamanca, 2004.

ARROYO ZAPATERO, L., «Legitimidad constitucional y conveniencia político-criminal de la Ley contra la violencia de género», en F. MUÑOZ CONDE (dir.), Problemas actuales del Derecho penal y la Criminología. Estudios penales en memoria de la Profesora Dra. Maria del Mar Díaz Pita, ed. Tirant lo Blanch, Valencia, 2008 .

ASÚA BATARRITA, A., «Los nuevos delitos de violencia doméstica tras la Reforma de la LO II/2003, de 29 de septiembre», en Cuadernos penales José María Lidón, I/2004.

BECCARIA, C., De los delitos y las penas, ed. Altaya, Madrid, i994.

BOIX REIG, J., Prólogo, en J. BOIX REIG, E. MARTÍNEZ GARCÍA (coords.), La nueva Ley contra la Violencia de Género, Iustel, Madrid, 2005.

COMAS D’ARGEMIR I CENDRA, M., QUERALT JIMÉNEZ, J., «La violencia de género: política criminal y ley penal», en AAVV, Homenaje al Profesor Dr. Gonzalo Rodríguez Mourullo, Thomson-Civitas, Navarra, 2005.

CRUZ BLANCA, M.J., «Derecho penal y discriminación por razón de sexo. La violencia doméstica en la codificación penal», en L. MORILLAS CUEVA (coord.), Estudios penales sobre violencia doméstica, ed. DIFUSA, Madrid, 2002.

CUGAT MAURI, M., «La ambivalencia de la protección de la libertad sexual. Jurisprudencia del Tribunal Supremo sobre el delito de violación», en Jueces para la Democracia, 20/1993.

DE FAZIO, L., <<Le vittime di stalking>>, en Modena Group on Stalking, Precosí di aiuto per vittime di stalking, Tipomonza, Milán, 2007.

DE LA MATA BARRANCO, N.J., El principio de proporcionalidad penal, ed. Tirant lo Blanch, Valencia, 2007

DÍAZ REVORIO, F.J., Las sentencias interpretativas del Tribunal Constitucional, ed. Lex Nova, Valladolid, $200 \mathrm{I}$.

FARALDO CABANA, P., «Razones para la introducción de la perspectiva de género en Derecho penal a través de la Ley Orgánica I/2004, de 28 de diciembre, sobre medidas de protección integral contra la violencia de género», en Revista Penal, I7/2006.

FARALDO CABANA, P., «Estrategias actuariales en el control penal de la violencia de género», en F. MUÑOZ CONDE (dir.), Problemas actuales del Derecho penal $y$ de la Criminología. Estudios penales en memoria de la Profesora Dra. María del Mar Díaz Pita, ed. Tirant lo Blanch, Valencia, 2008.

GARCÍA ALBERO, R., «Del quebrantamiento de condena», en G. QUINTERO OLIVARES (dir.), F. MORALES PRATS (coord.), Comentarios a la parte especial del Derecho penal, ed. Aranzadi, Pamplona, 2007.

GIMBERTANT ORDEIG, E., Prólogo a la I4ffi edición del Código penal de Tecnos, Madrid, 2008.

GONZÁLEZ RUS, J.J., «La constitucionalidad de la LO I/2004, de medidas de protección integral contra la violencia de género, en relación con la reforma de los delitos de lesiones, amenazas y coacciones», en J.C. CARBONELL MATEU y otros (coords.), Estudios penales en homenaje al Profesor Cobo del Rosal, ed. Dykinson, Madrid, 2005.

GONZÁLEZ RUS, J.J., «Las lesiones», en M. COBO DEL ROSAL, Derecho penal español. Parte especial, ed. Dykinson, Madrid, 2005.

LARRAURI PIJOÁN, E., «Igualdad y violencia de género», en InDret (www.indret.com), I/2009.

LARRAURI, E., Criminología crítica y violencia de género, ed. Trotta, Madrid, 2007.

LAURENZO COPELLO, P., «Los nuevos delitos de violencia doméstica: otra reforma precipitada», en F. PÉREZ ÁLVAREZ (dir.), Serta in memoriam Alexandri Baratta, ed. Servicio de Publicaciones de la Universidad de Salamanca, Salamanca.

LAURENZO COPELLO, P., «La violencia de género en la Ley integral. Valoración político criminal», en Revista Electrónica de Ciencia penal y Criminología (RECPC 07-08/2005).

MAQUEDA ABREU, M.L., «Feminismo y prostitución», El País, I de abril de 2006.

MAQUEDA ABREU, M.L., «La violencia de género: entre el concepto jurídico y la realidad social», en Revista Electrónica de Ciencia penal y Criminología (RECPC 08-02/2006).

MORALES PRATS, F., GARCÍA ALBERO, R., «De las agresiones sexuales», en G. QUINTERO OLIVARES (dir.), F. MORALES PRATS (coord.), Comentarios a la parte especial del Derecho penal, ed. Aranzadi, Pamplona, 2007.

RUBIDO DE LA TORRE, J.L., Ley de violencia de género. Ajuste de constitucionalidad en materia penal, ed. Tirant lo Blanch, Valencia, 2007.

TAMARIT SUMALLA, J.M., «Artículo I73», en G. QUINTERO OLIVARES (dir.), F. MORALES PRATS (coord.), Comentarios a la parte especial del Derecho penal, ed. Aranzadi, Pamplona, 2007. 
TERRADILLOS BASOCO, J.M., Peligrosidad social y Estado de derecho, ed. Akal, Madrid, I98I.

TERRADILLOS BASOCO, J.M., «Incidencia de la posición o situación personal, pública y privada, en la responsabilidad criminal», en Cuadernos de Derecho Judicial, Consejo General del Poder Judicial, VII/I995.

VILLACAMPA ESTIARTE, C., «El maltrato singular cualificado por razón de género. Debate acerca de su constitucionalidad», en Revista Electrónica de Ciencia Penal y Criminología (REPDC 09-12-2007), http://criminet.ugr.es/recpc.

ZAFFARONI, E.R., «El discurso feminista y el poder punitivo», en H. BIRGÍN (compilador), Las trampas del poder punitivo: el género en Derecho penal, Bilbos, Buenos Aires, 2000. 